\title{
Next Generation Nuclear Plant Licensing Basis Event Selection White Paper
}

The INL is a

U.S. Department of Energy National Laboratory

operated by

Battelle Energy Alliance

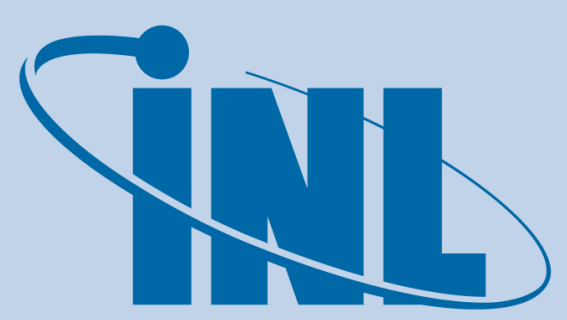

Idaho National Laboratory
September 2010

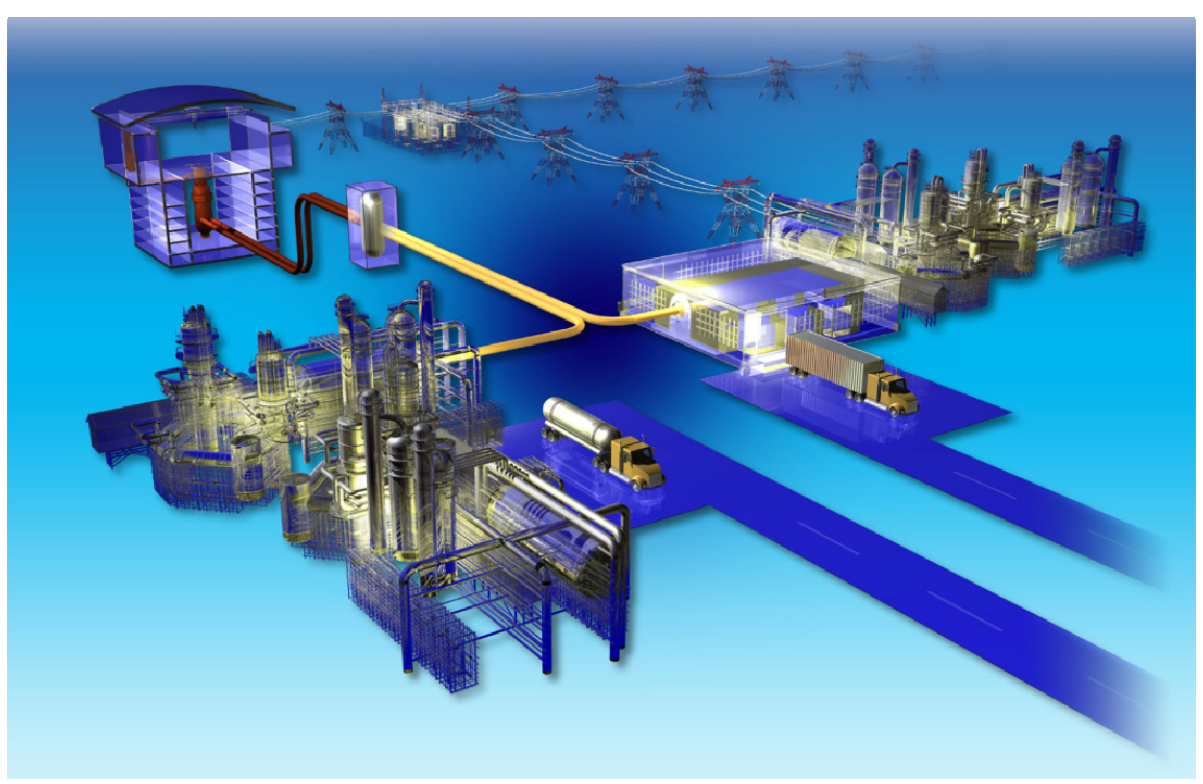




\section{DISCLAIMER}

This information was prepared as an account of work sponsored by an agency of the U.S. Government. Neither the U.S. Government nor any agency thereof, nor any of their employees, makes any warranty, expressed or implied, or assumes any legal liability or responsibility for the accuracy, completeness, or usefulness, of any information, apparatus, product, or process disclosed, or represents that its use would not infringe privately owned rights. References herein to any specific commercial product, process, or service by trade name, trade mark, manufacturer, or otherwise, does not necessarily constitute or imply its endorsement, recommendation, or favoring by the U.S. Government or any agency thereof. The views and opinions of authors expressed herein do not necessarily state or reflect those of the U.S. Government or any agency thereof. 


\section{Next Generation Nuclear Plant Licensing Basis Event Selection White Paper}

September 2010

Idaho National Laboratory

Next Generation Nuclear Plant Project

Idaho Falls, Idaho 83415

Prepared for the

U.S. Department of Energy

Office of Nuclear Energy

Under DOE Idaho Operations Office

Contract DE-AC07-05ID14517 
Next Generation Nuclear Plant Project

Next Generation Nuclear Plant Licensing Basis Event Selection White Paper

INL/EXT-10-19521

September 2010

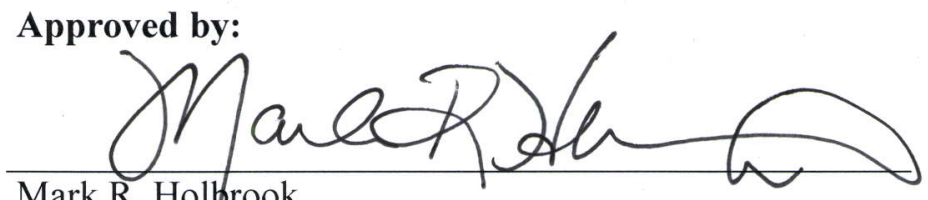

Mark R. Holbrook NGNP Regulatory Affairs

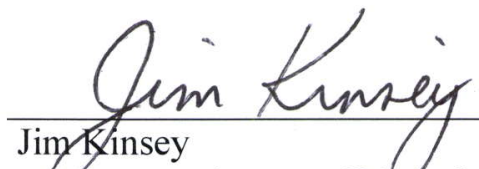

NGNP Regulatory Affairs Director

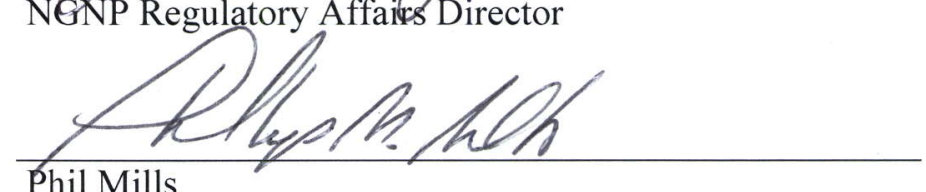

NGNP Engineering Director

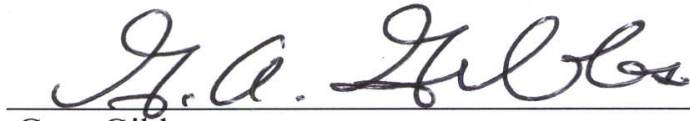

Greg Gibbs

NGNP Project Director
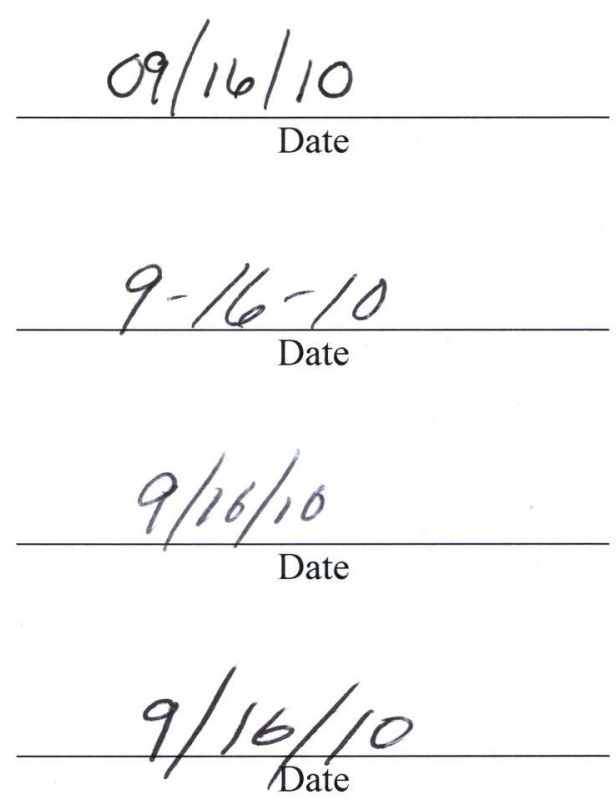


\begin{abstract}
The Next Generation Nuclear Plant (NGNP) will be a licensed commercial high temperature gas-cooled reactor (HTGR) capable of producing electricity and/or high temperature process heat for industrial markets supporting a range of end-user applications. The NGNP Project has adopted the 10 CFR 52 Combined License (COL) process, as recommended in the NGNP Licensing Strategy - A Report to Congress, dated August 2008, as the foundation for the NGNP licensing strategy. Nuclear Regulatory Commission (NRC) licensing of the NGNP plant utilizing this process will demonstrate the efficacy for licensing future HTGRs for commercial industrial applications. This white paper is one in a series of submittals that will address key generic issues of the priority licensing topics as part of the process for establishing HTGR regulatory requirements.

This white paper outlines the relevant regulatory policy and guidance for the spectrum of licensing basis events (LBEs) to be considered, describes the methodology for selecting and classifying LBEs, and sets forth issues for discussion in order to facilitate an effective submittal leading to an NGNP COL application under 10 CFR Part 52.

The information in this paper is intended to serve as the basis for interactions with the NRC staff. The NGNP Project wishes to obtain comments on the planned LBE selection/classification approach and feedback on a number of issues that have the potential to significantly impact the effort and schedule to prepare an application for the NGNP facility.
\end{abstract}




\section{CONTENTS}

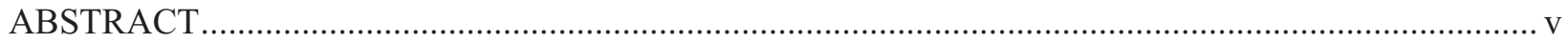

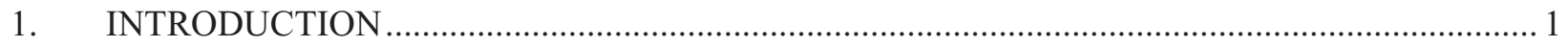

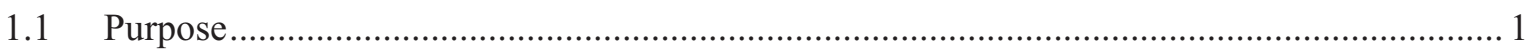

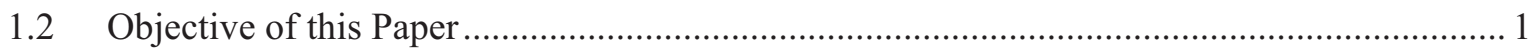

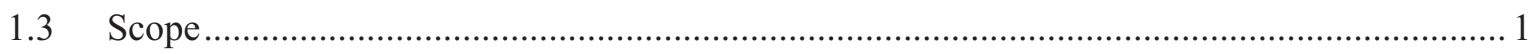

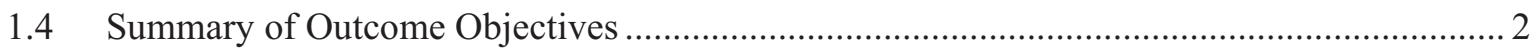

1.5 Relationship to Other NGNP Pre-Licensing Topics/Papers …........................................... 3

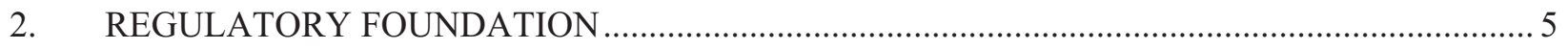

2.1 U.S. Regulatory Foundation for the Selection of LBEs .................................................... 5

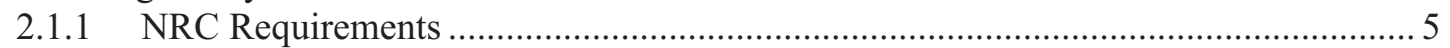

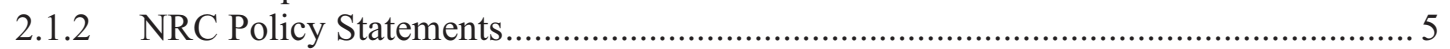

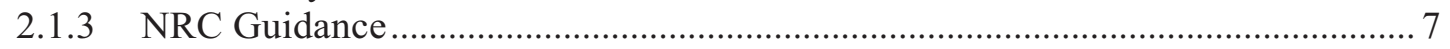

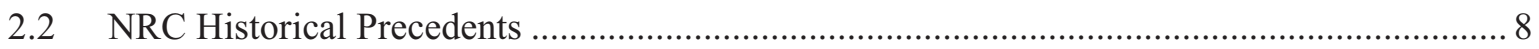

2.2.1 Modular High-Temperature Gas-Cooled Reactor................................................. 8

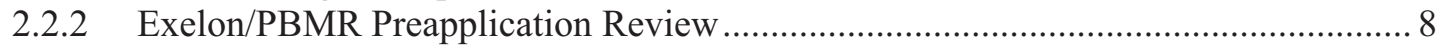

2.2.3 PBMR Responses to NRC Request for Additional Information ................................ 9

2.3 Regulatory Foundation for Establishing Top-Level Regulatory Criteria.............................. 9

2.3.1 TLRC Related to Normal Operation and AOOs ..................................................... 10

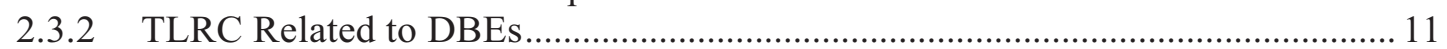

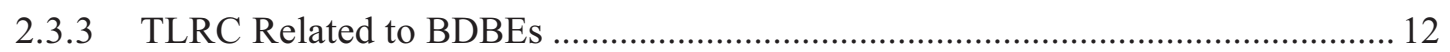

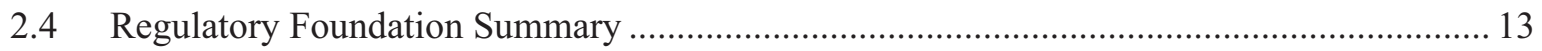

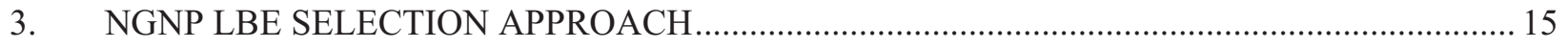

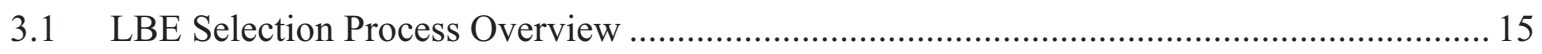

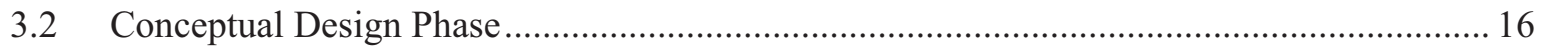

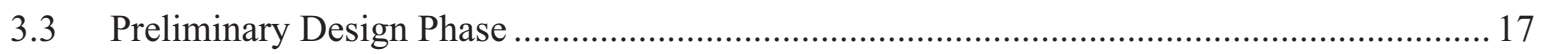

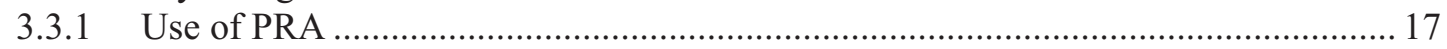

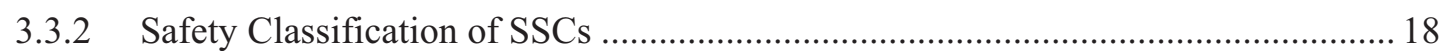

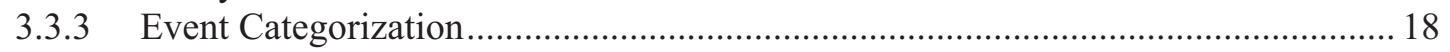

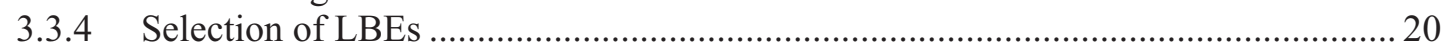

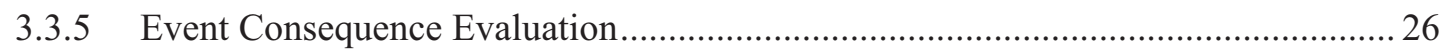

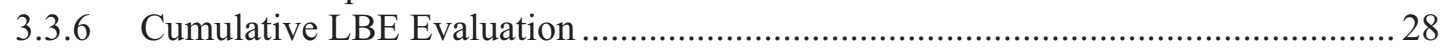

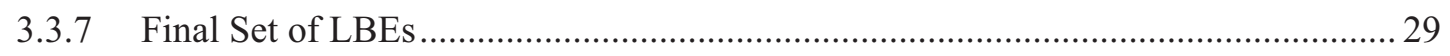

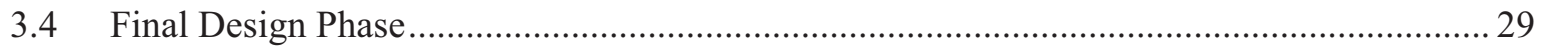

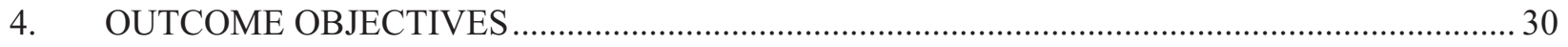

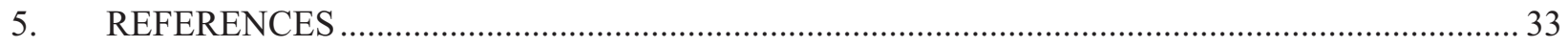




\section{FIGURES}

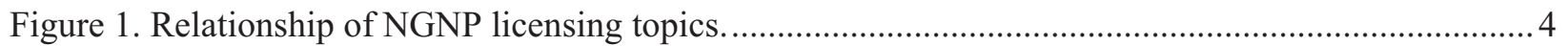

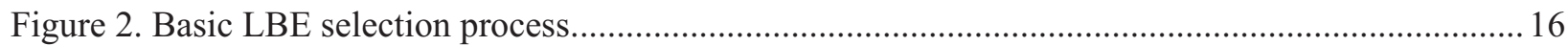

Figure 3. Frequency-consequence chart with top-level regulatory criteria...............................................20

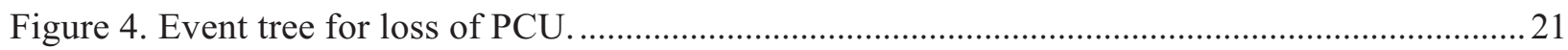

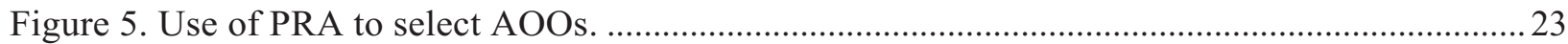

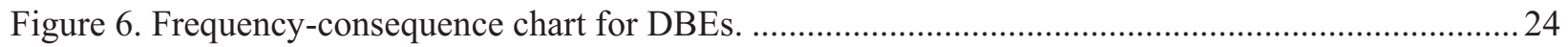

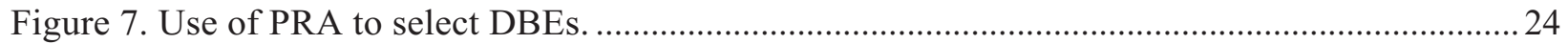

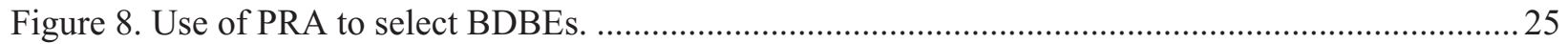

Figure 9. Example of DBA for main power system hx initiating event...............................................27 


\section{ACRONYMS}

ALARA as low as is reasonably achievable

AOO anticipated operational occurrences

BDBE beyond design basis event

CFR Code of Federal Regulations

COL Combined License

DBA design basis accident

DBE design basis event

DOE Department of Energy

EAB exclusion area boundary

GDC general design criteria

HTGR high temperature gas-cooled reactor

LBE licensing basis event

LOCA loss of coolant accident

LPZ low population zone

LWR light water reactor

MHTGR modular high-temperature gas-cooled reactor

NGNP Next Generation Nuclear Plant

NRC Nuclear Regulatory Commission

PAG Protective Action Guide

PBMR pebble bed modular reactor

PRA probabilistic risk assessment

QHO quantitative health objectives

RCCS Reactor Cavity Cooling System

RAI Request for Additional Information

SRP standard review plan

SSC structures, systems, and components

TEDE total effective dose equivalent

TLRC top-level regulatory criteria 
This page is intentionally left blank. 


\section{Next Generation Nuclear Plant Licensing Basis Event Selection White Paper}

\section{INTRODUCTION}

\subsection{Purpose}

The Next Generation Nuclear Plant (NGNP) license application will include a safety evaluation of a set of licensing basis events (LBEs). As the term is used in this paper, LBEs are defined as the events derived from the HTGR technology and plant design that are considered by the licensing process and are used in development of the license application. Defining LBEs creates a comprehensive set of event sequences that form the basis for plant analysis and represent the plant's characteristic performance in all analyzed frequency and consequence ranges. LBEs include conditions of normal operation, including anticipated operational occurrences (AOOs), infrequent design basis events (DBEs), and beyond design basis events (BDBEs) that inform the deterministically selected design basis accidents (DBAs).

This paper describes a systematic performance-based and risk-informed methodology for selecting and classifying LBEs for the NGNP design, consistent with the current Nuclear Regulatory Commission (NRC) policies and guidance on the application of deterministic design criteria and the use of probabilistic risk assessment (PRA) techniques. ${ }^{1,2}$ The methodology integrates the use of deterministic safety principles and PRA insights as critical inputs into the selection of LBEs. These events include specific scenarios to which mechanistic source terms are applied and assessed against offsite dose criteria.

The paper summarizes the methodology for determining the spectrum of LBEs to be considered, describes the approach for the selection and classification of the LBEs, and sets forth issues for review and discussion. In addition, this paper outlines the relevant regulatory policy and guidance for the spectrum of events to be considered.

\subsection{Objective of this Paper}

The objective of this paper is to reach NRC agreement on the approach for the selection and classification of LBEs to support the HTGR licensing process under Code of Federal Regulation (CFR) 10 CFR Part 52.

\subsection{Scope}

The approach described in this paper applies to both pebble bed and prismatic block reactor design types. This white paper discusses selection and classification of LBEs using criteria that focus on acceptable consequences to the public. Consequences to the worker are also important, but will be discussed at a later date, as will security-related events.

Section 2 of this white paper provides an overview of the regulations and guidance to be considered during development of the LBE selection and classification approach. Section 3 describes this approach and includes a discussion of how PRA techniques will be used. Section 4 summarizes the top priority licensing topics to be discussed with the NRC staff and examines how the NGNP approach meets the existing regulatory foundation in Section 2 and the guidance and precedents in this area. 


\subsection{Summary of Outcome Objectives}

The NGNP Project is seeking (1) NRC's general concurrences and/or comments on the adequacy of the planned LBE selection approach and (2) to obtain feedback from the NRC on any issues that have the potential to significantly impact the effort and schedule to prepare an application for a first-of-a-kind high temperature gas-cooled reactor (HTGR) plant under the NGNP Project. The NGNP Project is seeking agreement on its approach to selecting and classifying LBEs for the following specific areas:

1. The structured process for selecting LBEs is an acceptable approach for defining the LBEs.

2. LBEs cover a comprehensive spectrum of events from normal operation to rare, off-normal events. There are three categories of LBEs:

a. AOOs, which encompass planned and anticipated events. The doses from AOOs are required to meet normal operation public dose requirements. AOOs are utilized to set operating limits for normal operation modes and states.

b. DBEs encompass unplanned off-normal events not expected in the plant's lifetime, but which might occur in the lifetimes of a fleet of plants. The doses from DBEs are required to meet accident public dose requirements. DBEs are the basis for the design, construction, and operation of the structures, systems, and components (SSCs) during accidents.

c. BDBEs, which are rare off-normal events of lower frequency than DBEs. BDBEs are evaluated to ensure that they do not pose an unacceptable risk to the public.

The LBEs in all three categories will be evaluated individually to support the tasks of assessing the performance of SSCs with respect to safety functions in response to initiating events and collectively to demonstrate that the integrated risk of a multimodule plant design meets the NRC Safety Goals.

3. The frequencies of LBEs are expressed in units of events per plant-year where a plant is defined as a collection of reactor modules having certain shared systems. The limits on the frequency ranges for the LBE categories are as follows:
a. AOOs - event sequences with mean frequencies greater than $10^{-2}$ per plant-year
b. DBEs - event sequences with mean frequencies less than $10^{-2}$ per plant-year and greater than $10^{-4}$ per plant-year
c. BDBEs - event sequences with mean frequencies less than $10^{-4}$ per plant-year and greater than $5 \times 10^{-7}$ per plant-year.

4. Acceptable limits on the event sequence consequences and the analysis basis for the LBE categories are as follows:
a. AOOs - 10 CFR Part 20: 100 mrem total effective dose equivalent (TEDE) mechanistically modeled and realistically calculated at the exclusion area boundary (EAB). For the NGNP facility, the EAB is expected to be the same area as the controlled area boundary.
b. DBEs - 10 CFR $§ 50.34: 25$ rem TEDE mechanistically modeled and conservatively calculated at the EAB.
c. BDBEs - NRC Safety Goal quantitative health objectives (QHOs) mechanistically and realistically calculated at 1 mile $(1.6 \mathrm{~km})$ and 10 miles $(16 \mathrm{~km})$ from the plant.


5. The frequency below which events are not selected as LBEs is $5 \times 10^{-7}$ per plant-year. The PRA examines events to $10^{-8}$ per plant-year to assure that there are none just below this de minimus frequency.

6. The kinds of events, failures, and natural phenomena that are evaluated include:

a. Multiple, dependent, and common cause failures to the extent that these contribute to LBE frequencies

b. Events affecting more than one reactor module

c. Internal events (including transients and accidents) and internal and external plant hazards that occur in all operating and shutdown modes and potentially challenge the capability to satisfactorily retain any source of radioactive material.

7. The DBAs for Chapter 15, "Accident Analyses," of the license application are derived from the DBEs by assuming that only SSCs classified as safety-related are available to mitigate the consequences. The public consequences of DBAs are based on mechanistic source terms and are conservatively calculated. The upper bound consequence of each DBA must meet the 10 CFR $\$ 50.34$ consequence limit at the EAB.

8. Uncertainty distributions are evaluated for the mean frequency and the mean consequence for each LBE. The mean frequency is used to determine whether the event sequence family is an AOO, DBE, or BDBE. If the upper or lower bound on the LBE frequency straddles two or more regions, the LBE is compared against the consequence criteria for each region. The mean, lower, and upper bound consequences are explicitly compared to the consequence criteria in all applicable LBE regions. The upper bound for the DBE and DBA consequences must meet the 10 CFR $\$ 50.34$ dose limit at the EAB.

\subsection{Relationship to Other NGNP Pre-Licensing Topics/Papers}

This white paper is one of several white papers covering key regulatory issues that are being prepared and submitted for NRC review and comment as part of the NGNP Project licensing strategy. Some of these other white papers have bearing on the development of the methodology for selecting LBEs or will rely on the process outlined in this paper. NGNP priority licensing topics are summarized in the NGNP Licensing Plan (INL 2009). The papers that have the most direct relationship with this paper include:

- SSC Safety Classification

- $\quad$ NGNP Defense-in-Depth Approach

- Air and Water Ingress

- Mechanistic Source Terms

- Integrated Risk, Use of PRA 
The relationships between these licensing topics and this white paper are depicted in Figure 1.

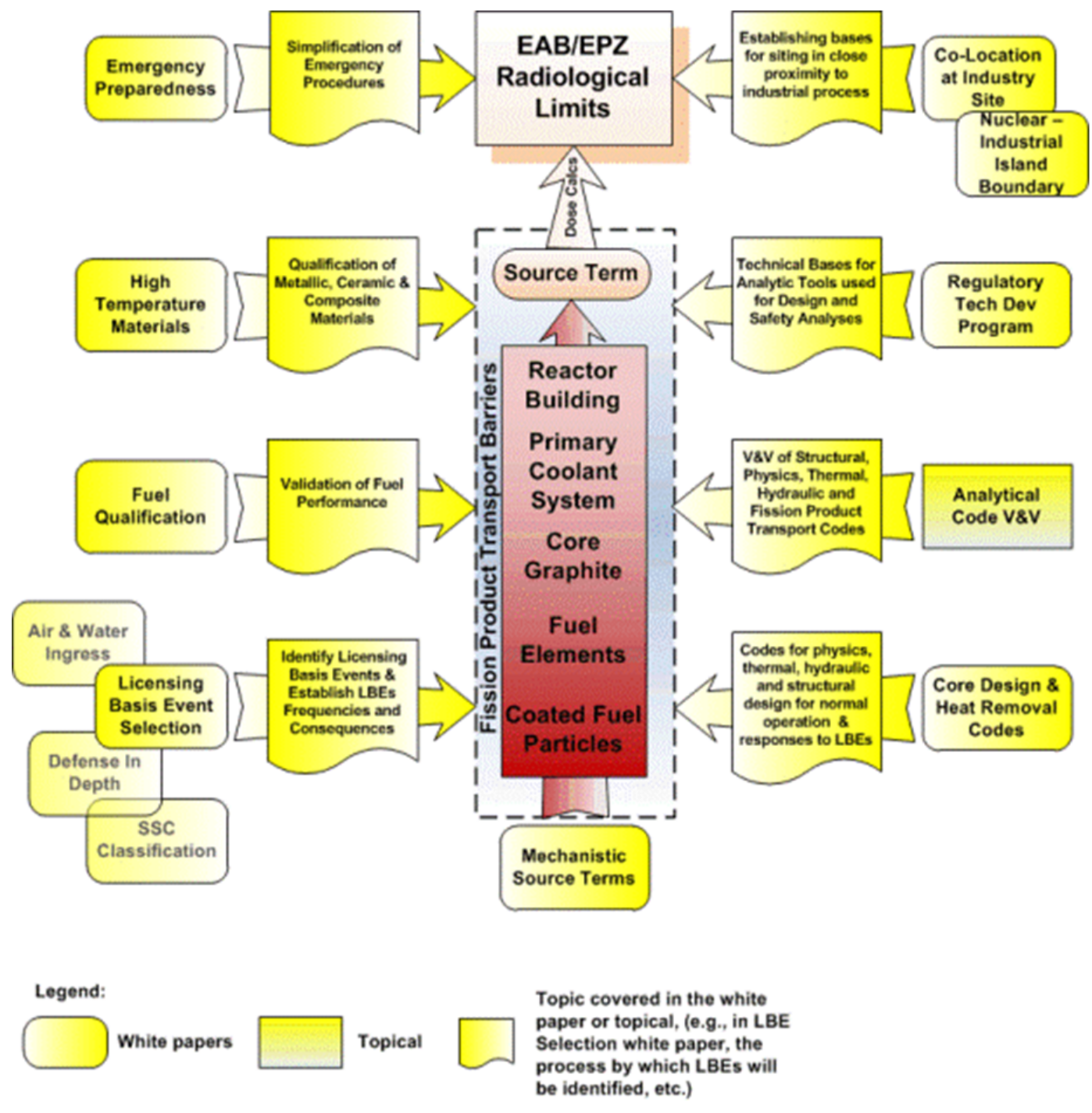

Figure 1. Relationship of NGNP licensing topics. 


\section{REGULATORY FOUNDATION}

NRC regulations, policies, and guidance that are relevant to the definition of LBEs and their treatment are discussed in this section. These regulatory criteria are examined to investigate two aspects of the proposed risk-informed approach for the NGNP project. The first is the process of selecting the LBEs and the second is the development of the top-level regulatory criteria (TLRC) that establish limits on the frequencies and public radiological consequences used to classify and evaluate the LBEs.

\subsection{U.S. Regulatory Foundation for the Selection of LBEs}

\subsubsection{NRC Requirements}

NRC regulatory requirements for the design of currently licensed reactors divide LBEs into three categories: normal operations, including AOOs; unplanned, off normal events and DBEs ${ }^{\text {a }}$; and BDBEs, including severe accidents.

For normal operations, including AOOs, the NRC regulations are, for the most part, generic and generally apply to the NGNP facility as discussed in Section 2.2.1.

However, the regulations that have evolved for unplanned transients and accidents are light water reactor (LWR)-specific. For LWRs, the general design criteria (GDC) in Appendix A to 10 CFR Part 50 indicate that loss-of-coolant accidents (LOCAs) must be postulated in designing systems, and the GDC define the types of design considerations that apply to the design of SSCs that prevent or mitigate postulated accidents. For example, GDC typically indicate that safety systems must be able to perform their design basis functions given a single active failure and a concurrent loss of offsite power.

With limited exceptions, NRC's regulations do not have criteria to limit the consequences or frequency of BDBEs. The exceptions pertain to limited categories of events such as: anticipated transients without scram addressed in 10 CFR $\$ 50.62$, station blackout addressed in 10 CFR $\$ 50.63$, functions such as combustible gas control addressed in $10 \mathrm{CFR} \S 50.44$, and large commercial aircraft impacts addressed in 10 CFR50.150.

\subsubsection{NRC Policy Statements}

The HTGR design is subject to non-LWR application policy requirements. The license application intends to comply with this guidance and meet these policy requirements. The NGNP licensing approach described in this and related papers respond to the Advanced Reactor Policy that encouraged innovative licensing approaches. ${ }^{3}$

\subsubsection{Policy on the Regulation of Advanced Reactors}

On October 14, 2008, the NRC published its revised policy regarding its expectations for the regulation of advanced reactors. ${ }^{3}$ For advanced reactor designs like the NGNP design, the NRC expects at least the same degree of protection of the environment, public health and safety, and common defense and security that is required for current generation LWRs. The NRC also expects that advanced reactors will provide enhanced margins of safety and/or use simplified, inherent, passive, or other innovative means to accomplish their safety and security functions.

a. LWR regulatory terminology has historically used the term "accidents" to describe deterministically selected events for analysis. Consistent with current regulatory practice, this LBE selection approach uses "event" terminology to describe probabilistically selected events. The term "design-basis accidents" (DBEs) is assigned to those events that are analyzed conservatively and found in Chapter 15 of the Final Safety Analysis Report. 
SECY 2002-0076, "Semi-Annual Update of the Future Licensing and Inspection Readiness Assessment," described Exelon's proposed licensing approach for the pebble bed HTGR design. Exelon proposed conformance with current regulations but recognized that many of the regulatory requirements were based on LWR technology. A risk-informed process would be employed to define plant design events, acceptance criteria, and SSCs. In its preliminary evaluation, NRC staff concluded that the proposed licensing approach, if adequately implemented, was a reasonable process for ensuring that the Commission's regulations would be met and for identifying pebble bed modular reactor (PBMR)-specific regulatory requirements.

SECY 2003-0047, "Policy Issues Related to Licensing Non-Light Water Reactor Designs"4 offers staff recommendations on several relevant policy issues that had been originally defined in an earlier policy statement (SECY 2002-0139). Of these issues, Issue 4, "Use of PRA to Support Licensing Basis," specifically relates to the treatment of LBEs and is discussed herein. The Staff Requirements Memorandum (SRM) for SECY 2003- $0047^{5}$ stated the Commissioners approval of the staff recommendations on this issue.

With respect to Issue 4, the staff recommended that the Commission take the following actions:

- Modify the Commission's guidance, as described in the SRM of July 30, 1993, to put greater emphasis on the use of risk information by allowing the use of a probabilistic approach in the identification of events to be considered in the design, provided there is sufficient understanding of plant and fuel performance and deterministic engineering judgment is used to bound uncertainties.

- Allow a probabilistic approach for the safety classification of structures, systems, and components.

- Replace the single failure criterion with a probabilistic (reliability) criterion.

- This recommendation is consistent with a risk-informed approach. It should be noted that this recommendation expands the use of probabilistic risk assessment (PRA) into forming part of the basis for licensing and thus puts greater emphasis on PRA quality, completeness, and documentation.

Also included, but left unresolved from the issues of SECY 2003-0047, were policy issues associated with the treatment of integrated risk on multimodule sites and for modular reactor designs, which are part of Issue 1 as stated in the SECY.

SECY 2010-0034, "Potential Policy, Licensing, and Key Technical Issues for Small Modular Nuclear Reactor Designs," identifies a number of potential policy and licensing issues based on the preliminary design information provided by preapplicants and discussions with the designers and DOE regarding their proposed approaches to addressing key issues. Issues included accident selection for small modular reactors. With respect to this issue, the staff noted:

In the August 2008 NGNP Licensing Strategy, the Commission stated that licensingbasis event categories (i.e., abnormal occurrences, design-basis accidents, and beyonddesign basis accidents) would be established based on the expected probability of event occurrence. However, selection of licensing basis events within each category would be performed using deterministic engineering judgment complemented by insights from the NGNP PRA. In general, the NRC staff expects to apply this approach to all SMRs.

Although identification of many accident scenarios will likely be straightforward, the application of certain scenarios may require Commission consideration. For example, designers of HTGRs have previously proposed that the failure of the vessel or piping 
connecting the reactor vessel and steam generator vessel need not be considered as a design basis event. In addition, although the Commission has previously stated that certain events should be addressed for non-LWR designs, subsequent research and evaluations may challenge the need to analyze these low probability events.

The NRC staff plans to develop proposed resolutions to the issues in SECY 2010-0034 by continuing to obtain information from DOE, potential design and license applicants, and other sources; identifying and developing proposals for the resolution of policy issues; and where appropriate, preparing papers proposing resolutions of these issues with recommendations for consideration and approval by the Commission.

\subsubsection{NRC Guidance}

NRC guidance provides more detail on the type of accidents that constitute DBAs and transients for the currently licensed LWRs. In particular, NUREG-0800, "Standard Review Plan (SRP)," ${ }^{6}$ identifies the types of AOOs and DBAs that must be postulated for LWRs. There is no comparable guidance for HTGRs. As discussed above, the NGNP project approach for selection of LBEs utilizes deterministic insights supplemented by PRA.

In its June 26, 1990, SRM on SECY-90-16, ${ }^{7}$ the Commission endorsed a core damage frequency (CDF) goal of $10^{-4}$ per year for advanced reactors. Since accidents involving core damage in HTGRs are BDBEs (based on the HTGR particle fuel's resistance to melting under high temperature conditions), this implies that DBAs in general have a collective frequency greater than $10^{-4}$ per year. $^{\mathrm{b}}$

The NRC has not established a lower bound for the frequency of severe accidents that need to be considered. However, in general, the NRC does not require consideration of accidents that are not deemed to be 'credible.' Additionally, Regulatory Guide 1.174, Section 2.2.4, states that an increase in core damage frequency of less than $10^{-6}$ per year and an increase in large early release frequency of $<10^{-7}$ per year are considered 'very small' and consistent with the Commission's Safety Goal Policy. These criteria are repeated in Section III.2.2.5 of SRP 19, "Use of Probabilistic Risk Assessment in Plant-Specific RiskInformed Decision-making: General Guidance." ${ }^{8}$ Additionally, SRP 19 states that a PRA may have a truncation limit that, depending on the level of PRA detail (module level, component level, or piece-part level), may be from $10^{-12}$ to $10^{-8}$ per reactor-year. Similarly, Regulatory Guide 1.200, "An Approach for Determining the Technical Adequacy of Probabilistic Risk Assessment Results for Risk-informed Activities," "Section 1.2.5, states that an external event may be screened out of a PRA if it can be shown that the mean value of the frequency of the corresponding design-basis hazard used in the plant design is less than $10^{-5}$ per year and that the conditional core-damage probability is less than $10^{-1}$, given the occurrence of the design-basis hazard. These guidelines indicate that events that have a frequency lower than $\sim 10^{-6}$ or $10^{-7}$ per year do not need to be evaluated, and that events with a probability of less than about $10^{-8}$ may be screened from the PRA.

b. Note that some postulated LWR DBAs, such as double-ended guillotine breaks of large pipes, may have significantly lower frequencies than $10^{-4}$ per year. 


\subsection{NRC Historical Precedents}

\subsubsection{Modular High-Temperature Gas-Cooled Reactor}

In the late 1980s and early 1990s, the NRC conducted a preapplication review of the modular hightemperature gas-cooled reactor (MHTGR) at the request of the Department of Energy (DOE). DOE proposed a systematic, structured method for selecting LBEs that used a top-down approach based on toplevel regulatory criteria and PRA. The approach identified three licensing basis event regions (AOOs, DBEs, and Emergency Planning Basis Events) and used a frequency-consequence risk plot.

The NRC published preliminary results of its MHTGR review in NUREG-1338, "Draft Preapplication Safety Evaluation Report for the Modular High-Temperature Gas-Cooled Reactor." In Sections 3.1.2 of NUREG-1338, the NRC stated that:

The staff concludes that the DOE's approach is a systematic and useful approach for design of a nuclear plant. However, it is not an adequate replacement for the application of NRC's regulatory approach to the safety and licensing review. Specifically, the staff found, as a result of review of the MHTGR, that many regulatory criteria (10 CFR) and much Standard Review Plan (NRC report NUREG-0800) guidance are applicable to the MHTGR, and the application of these criteria is necessary to ensure that the MHTGR achieves at least an equivalent level of safety as that of current-generation LWRs.

\subsubsection{Exelon/PBMR Preapplication Review}

In 2001 to 2002, the NRC staff conducted a preapplication review of the PBMR design at the request of Exelon. In a letter to Exelon dated March 26, 2002, the NRC staff provided its assessment of the licensing approach proposed by Exelon, including the TLRC. With respect to selection of TLRC, the NRC staff stated:

The staff notes that plotting of TLRC is useful to illustrate bounding criteria and safety margins. However, the licensing basis is the set of requirements that are applied to the safety-related equipment to meet the LBEs (or other special regulatory objectives such as anticipated transients without scram (ATWS) or station black-out (SBO)); simply falling within the plot of the TLRC does not in itself constitute a complete licensing basis. Moreover, while the PRA confirms risk insights for a design, and can be used for other purposes as noted above, licensing activities will be a mix of "deterministic" analysis supplemented with risk insights.

With respect to selection of LBEs, the NRC staff stated:

In the SRM for SECY-93-092, "Issues Pertaining to the Advanced Reactor (PRISM, MHTGR, and PIUS) and CANDU 3 Designs and their Relationship to Current Regulatory Requirements," issued April 8, 1993, regarding accident selection and evaluation, the Commission approved the staff recommendation that events and sequences be selected deterministically and use conservative assumptions, and be supplemented with insights from the PRA for the specific design. In Exelon's August 31, 2001, document containing its proposed licensing approach, Exelon appears to be using probabilistic criteria to select AOOs, DBEs, and EPBEs. However, from verbal interactions with Exelon, the staff believes that the candidate LBEs which will be considered for application within the framework of the TLRC will first be established

c. USNRC, NUREG-1338, 'Draft Preapplication Safety Evaluation Report for the Modular High-Temperature Gas-Cooled Reactor (MHTGR),’ March 1989. 
deterministically, and will then be assessed and compared to the TLRC using risk insights. To the extent Exelon adheres to such an approach, the staff believes it would be consistent with previous Commission guidance.

Following the Exelon review, the NRC staff provided the Commission a status report on the policy implications from licensing non-LWR designs and the staff's plans for seeking Commission guidance on resolving the issues. Three overarching policy issues and four policy issues of a more specific nature were discussed in SECY-02-0139. Of the seven issues, Issue 4, "To what extent should a probabilistic approach be used to establish the plant licensing basis?" specifically relates to LBE selection. The Commission approved the staff's recommendation in the "Staff Requirements Memorandum on SECY-03-0047" to allow the use of a probabilistic approach in the identification of events (See Section 2.1.2.1 of this white paper for additional details).

The NRC findings in these reviews for the DOE MHTGR and the Exelon PBMR licensing approaches have been considered in the approach that is described in Section 3.

\subsubsection{PBMR Responses to NRC Request for Additional Information}

This paper on LBE selection draws from the PBMR preapplication white paper submitted to the NRC on July 3, 2006. ${ }^{\mathrm{d}}$ In its letter of September 24, 2007, ${ }^{\mathrm{e}}$ the NRC sent Requests for Additional Information (RAIs) on white papers that had been submitted by PBMR to the NRC for review, including the LBE Selection white paper. Responses to these RAIs were provided by PBMR on March 21, 2008. ${ }^{\mathrm{f}}$ Subsequent to the provision of responses to the RAIs, the PBMR licensing project activities were discontinued, and the RAI responses were not reviewed by the NRC.

\subsection{Regulatory Foundation for Establishing Top-Level Regulatory Criteria}

The focus of this section is to define criteria that establish limits on the frequencies or consequences of LBEs and LBE categories that must be considered in the design and operation of a nuclear power plant in order to assure public safety and to assess the adequacy of the performance of SSCs that perform safety functions during these LBEs. The TLRC are based on the following objectives:

1. Provide direct public health and safety acceptability limits in terms of individual radiological consequences

2. Are independent of HTGR reactor type and site

3. Provide well-defined, quantifiable risk criteria.

The following primary sources have been identified as containing criteria that establish limits on the risk or consequences of potential radiological releases from nuclear power plants in the United States.

- $\quad$ Reactor Safety Goal Policy Statement (51 FR 28044): On August 4, 1986, the NRC adopted a safety goal policy for the operation of nuclear power reactors. ${ }^{10}$ The objective of this policy is to establish goals that broadly define an acceptable level of radiological risk. Two qualitative safety goals supported by two quantitative objectives were established. These two supporting objectives are based on the principle that nuclear risks should not be a significant addition to other societal risks.

d. Edward G. Wallace letter to NRC Document Control Desk, "PBMR White Paper: LBE Selection,” July 3, 2006.

e. NRC letter to PBMR, "Requests For Additional Information Regarding Pebble Bed Modular Reactor (PBMR) PreApplication White Papers," September 24, 2007.

f. PBMR Limited letter to NRC, "Response to Requests for Additional Information," March 21, 2008. 
This policy limits public safety risk resulting from nuclear power plant operation. Limits are stated in the form of the maximum allowable risk of immediate death and the risk of delayed mortality from exposure to radiological releases of all types from nuclear power plants.

- 10 CFR Part 20, "Standards for Protection against Radiation (Subpart C, Occupational Dose Limits)": The regulations promulgated under 10 CFR Part 20 establish standards for protection against ionizing radiation resulting from activities conducted under licenses issued by the NRC. Event sequences expected to occur within the HTGR plant lifetime, considering multiple reactor modules, are classified as AOOs. AOOs are evaluated against the dose limits of 10 CFR Part 20.

- 10 CFR Part 20, "Standards for Protection against Radiation (Subpart D, Radiation Dose Limits for Individual Members of the Public)": These criteria (\$20.1301) limit the dose consequences of releases associated with relatively high frequency events that occur as part of normal plant operations.

- 10 CFR Part 50, Appendix I, "Numerical Guides for Design Objectives and Limiting Conditions for Operation to Meet the Criterion 'As Low as is Reasonably Achievable' for Radioactive Material in Light-Water-Cooled Nuclear Power Reactor Effluents": This appendix provides explicit limits on doses from planned discharges that meet the NRC's definition of ALARA.

- 10 CFR Part 52, Subpart C, "Combined Licenses": Under the provisions of 10 CFR $\$ 52.79$, an application for a combined license must include the principal design criteria for a proposed facility. The principal design criteria establish the necessary design, fabrication, construction, testing, and performance requirements for SSCs important to safety; that is, SSCs that provide reasonable assurance that the facility can be operated without undue risk to the health and safety of the public.

- 40 CFR Part 190, "Environmental Radiation Protection Standards for Nuclear Power Operations": These standards provide the generally applicable exposure limits for members of the general public from all operations except transportation and disposal or storage of spent fuel associated with the generation of electrical power by nuclear power plants.

- 10 CFR Part 100, "Reactor Site Criteria (Subpart B, Evaluation Factors for Stationary Power Reactor Site Applications on or After January 10, 1997)": $§ 100.20$ defines the EAB and low population zones (LPZs) of a nuclear reactor site, and requires that the combination of the site and reactor located on that site be capable of meeting the dose and dose rate limitations set forth in 10 CFR $§ 50.34(a)$.

- $\quad 10$ CFR §50.34(a)(ii)(D), “Contents of Applications: Technical Information (Radiological Dose Consequences)": This section of the regulation specifies dose limits for evaluating the acceptance of the engineered safety features that are intended to mitigate the radiological consequences of accidents. These dose limits are consistent with those utilized in 10 CFR Part 100 for determining the extent of the EAB and Emergency Planning Zone (EPZ).

Each of these primary sources is discussed in greater detail below. They have been grouped into three sets of criteria, consistent with the category of event(s) to which they apply.

\subsubsection{TLRC Related to Normal Operation and AOOs}

The U.S. Environmental Protection Agency is the agency given the authority to set generally applicable regulations governing the acceptable level of radiological exposure to members of the public. Specifically, 40 CFR $\S 190.10$ (a) states that the annual dose equivalent to a member of the general public from planned uranium fuel cycle operations shall be $<25 \mathrm{mrem}$ to the whole body, $<75 \mathrm{mrem}$ to the thyroid, and $<25 \mathrm{mrem}$ to any other organ. Portions of these exposure limits must be allocated to the various elements comprising the uranium fuel cycle (e.g. uranium mining and milling, fuel production, and reactor operations to produce electrical power). While the definition of 'uranium fuel cycle 
operations' specifically references the production of electric power by LWRs, the inclusion of the alternative term 'nuclear fuel cycle' in the definitions section of the regulation, as well as its formal title, "Environmental Radiation Protection Standards for Nuclear Power Operations," can be inferred to mean that it applies to other types of nuclear fuel as well as other types of reactors. Variances from these limits are allowed for unanticipated occurrences that still fall within the category of normal operations.

The NRC is the agency directly responsible for regulating the operation of nuclear power plants. As such, it is authorized to develop its own regulations, consistent with the requirements of 40 CFR Part 190, to ensure the health and safety of the general public. In exercising this responsibility, the NRC has promulgated a number of regulations that limit doses to the public from anticipated and unanticipated events during normal reactor operations.

10 CFR §50.34, 10 CFR Part 20, and Appendix I of 10 CFR Part 50 all provide guidance on the limits for radiological releases from reactors during normal operations.

10 CFR §50.34(b)(3) states that the means for controlling and limiting effluent releases and radiation exposures during operation shall be capable of meeting the requirements set forth in 10 CFR Part 20. 10 CFR $\$ 20.1301$ requires that the TEDE for a member of the public be limited to 100 mrem per year and 2 mrem in any 1 hour, in unrestricted areas. This regulation provides the applicable criteria for limiting dose to the general public from anticipated and unanticipated events associated with the normal (nonaccident) operation of a nuclear power plant.

10 CFR Part 50, Appendix I, identifies dose and dose rate limits and limits on planned releases from the operation of nuclear power plant radwaste systems during normal operation, to maintain exposures ALARA. These criteria provide implementation guidance for applying the requirements of 10 CFR $\S 50.34(a)$ and $\$ 50.36(a)$, for planned releases from the radwaste systems of nuclear power plants to the general environment to be ALARA. These ALARA limits are small fractions of the limits imposed by 10 CFR Part 20.

In setting its own quantitative limits on radiation exposure limits for the operation of nuclear power plants, the NRC has made use of the variance provided in 40 CFR $\$ 190.11$ discussed earlier. The higher exposure limits set by 10 CFR Part 20 are associated with events still considered to lie within the regime of normal operations, but which are not considered to be 'planned' events as that term is used in 40 CFR Part 190.

The regulations do not define the term 'normal operation' in quantitative terms, i.e., the expected frequency of specified anticipated occurrences. However, Appendix A to 10 CFR Part 50 defines AOOs as "those conditions of normal operation... expected to occur one or more times during the life of a nuclear power plant."

\subsubsection{TLRC Related to DBEs}

10 CFR $\S 50.34(a)(1)$ contains NRC's regulations governing the design of new reactors and the means provided to protect against DBAs. As noted in the Footnote a, this LBE selection approach uses the term 'events' in lieu of 'accidents' (as found in the regulations discussed below) for the identification of unplanned, off-normal events not expected in the plant lifetime.

10 CFR $§ 50.34(a)(1)$ requires that any reactor be designed such that:

- An individual located at any point on the EAB would not receive a radiation dose in excess of 25 rem TEDE for any 2-hour period following the onset of a postulated fission product release. 
- An individual located at any point on the outer boundary of the LPZ, exposed to the radioactive cloud resulting from a postulated fission product release, would not receive a radiation dose in excess of 25 rem TEDE.

10 CFR §50.34(a)(ii)(D) requires that these consequence limits be used when evaluating the acceptability of the features included in the plant design (i.e., engineered safety features and fission product barriers) for mitigating accident radioactive releases. The footnote pertaining to this section states that the fission product release to be assumed should be based "upon a major accident... postulated from consideration of possible accidental events." 10 CFR §100.21(c)(2), "Reactor Site Criteria: non-seismic site criteria," requires that the radiological dose consequences of postulated accidents meet the criteria stated in 10 CFR $\$ 50.34(a)(1)$ for the type of facility located at the site in question.

In general, NRC's regulations do not define the type of events that comprise the category of DBAs. For LWRs, the GDC (Appendix A to 10 CFR Part 50) indicates that LOCAs must be considered as postulated accidents when designing safety systems. However, the category of 'postulated accidents' may include other types of events.

The regulations do not define DBAs in terms of their expected frequencies of occurrence, but 10 CFR $\$ 50.34(a)(i)(2)$ articulates the expectation that the design, construction, and operation of nuclear power reactors will be such as to produce an 'extremely low probability of occurrence' for accidents that could release significant quantities of radioactive fission products. No quantitative definition of the term 'extremely low probability' is provided in the regulation.

\subsubsection{TLRC Related to BDBEs}

Current policy and guidance require that certain events outside the scope of the normal operation and DBE categories be considered in the design of nuclear power plants.

The NRC's "Policy Statement on Severe Reactor Accidents Regarding Future Designs and Existing Plants" ${ }^{11}$ states the Commission's intent to "...take all reasonable steps to reduce the chances of occurrence of a severe accident involving substantial damage to the reactor core and to mitigate the consequences of such an accident should one occur." As noted earlier, this policy statement specifically addresses the Commission's intent to resolve safety issues associated with "accidents more severe than design basis accidents." This policy statement also makes the following points with respect to the design and licensing of new nuclear power plants:

- New plants are expected to achieve a higher standard of severe accident safety performance than existing plants.

- Innovative, cost-effective ways of achieving improved overall reliability for systems that prevent or mitigate the consequences of severe accidents are supported by the NRC.

Analyses of events beyond the design basis should be as realistic as possible, and make use of the insights provided by PRA.

In addition to its Severe Accident Policy, the Commission has issued NUREG-0880, "Safety Goals for Nuclear Power Plant Operation" 13 and the related policy statement entitled "Safety Goals for the Operations of Nuclear Power Plants."10 Two qualitative safety goals are used to express the Commission's policy regarding the acceptable level of radiological risk from nuclear power plant operation as follows: 
Individual members of the public should be provided a level of protection from the consequences of nuclear power plant operation such that individuals bear no significant additional risk to life and health.

Societal risks to life and health from nuclear power plant operation should be comparable to or less than the risks of generating electricity by viable competing technologies and should not be a significant addition to other societal risks.

The following quantitative health objectives were identified as the basis for determining achievement of the above safety goals:

- The risk to an average individual in the vicinity of a nuclear power plant of prompt fatalities that might result from reactor accidents should not exceed onetenth of one percent ( 0.1 percent) of the sum of prompt fatality risks resulting from other accidents to which members of the U.S. population are generally exposed.

- The risk to the population in the area near a nuclear power plant of cancer fatalities that might result from nuclear power plant operation should not exceed one-tenth of one percent ( 0.1 percent) of the sum of cancer fatality risks resulting from all other causes.

The statement of risks provided in the Safety Goal Policy envelops the spectrum of allowable risk associated with the operation of a nuclear power plant. As such, it clearly defines the outermost boundaries of acceptable risk associated with any event that has the potential to produce a radiological release affecting the environment or the health and safety of the general public.

\subsection{Regulatory Foundation Summary}

There are a number of NRC criteria that explicitly constrain the risk and/or allowable consequences of radiological releases from nuclear power plants. These criteria include requirements to evaluate the adequacy of the proposed design of the plant against specific limits.

NRC regulations and policies also recognize the categorization of events, generically termed Licensing Basis Events or LBEs in this paper, that fall into three distinct categories: normal operation or AOOs; DBAs or DBEs as described in this paper; and BDBEs.

All but one of the criteria described in this section provide their guidance in terms of consequence or release limits, not in the context of individual radiological risk as such. The exception is the Safety Goal Policy, which specifies two quantitative risk metrics. Each of the other regulatory requirements discussed in this section may be regarded as providing useful risk limitation guidance, because it is possible to associate types of events with particular frequency and consequence or release limits. For example:

1. CFR Part 20,10 CFR Part 50 Appendix I, 40 CFR Part 190, and 10 CFR §50.34(b) pertain to normal operations and AOOs. These types of events would be expected to occur sometime during the operational life of a plant.

2. 10 CFR $\$ 50.34$ (a) pertains to DBEs that are not expected to occur during the life of a plant but could reasonably occur within the operational life of a large fleet of plants.

3. The Safety Goal Policy generally pertains to accidents within and beyond the design-basis of the plant.

Additional sources of information on the applicability of the criteria cited above exist in other forms, such as implementation guidance provided by NRC Regulatory Guides or in NUREGs (as noted in 
NUREG-1338; see Section 2.2.1). These sources offer additional relevant information for development of LBEs. One other source of information that is useful in defining the HTGR licensing basis is the record of licensing submittals and decisions pertaining to the MHTGR and PBMR projects. 


\section{NGNP LBE SELECTION APPROACH}

The NGNP project is developing a risk-informed and performance-based technical approach that uses deterministic judgment/analysis and probabilistic techniques. This approach will systematically adapt applicable NRC LWR technical licensing requirements in establishing HTGR design-specific technical licensing requirements. This section describes how these elements work together for selection and classification of LBEs and satisfy the regulatory foundation described in Section 2.

\subsection{LBE Selection Process Overview}

The HTGR design will be developed using a systematic, top-down approach to regulatory and enduser requirements. Conventional engineering design and analysis techniques will be used to make design selections to satisfy these requirements, and existing HTGR experience will be used by the design process. Regulatory requirements must include nuclear safety considerations to protect the offsite public and onsite workers from radioactive materials. These include defense-in-depth considerations that prevent and mitigate postulated nuclear accidents.

As noted in Section 1.1 of this paper, LBEs are defined as the events derived from the HTGR technology and plant design that are considered by the licensing process and are used to derive design specific performance requirements for SSCs. A combination of deterministic and probabilistic analysis is used to identify these events and evaluate the event sequences. The LBE selection process will identify event sequence families based on an identified set of initiating events and will establish the frequency of each of these event sequences.

Although this process informs the design requirements of safety-related SSCs and SSCs important to safety, LBE selection is also an integral part of the overall design process. Clearly the design attributes of the plant influences the type and sequence of events of LBEs, but the identified LBEs can, in turn, affect the final design. Once an initial set of LBEs is identified, the design can be refined to reduce the frequency or consequence of a given LBE. This suggests an iterative design process where more design and analysis detail is available at each phase. During the detailed design development - conceptual, preliminary, and final design phases - a process similar to that shown in Figure 2 will be used. For each phase:

1. A deterministic approach is used to select an initial event set providing a starting point for a given phase of the design process. For example, a set of initial events developed from conceptual design provides the starting point for preliminary design.

2. The LBEs are updated as the design and analysis progress. The PRA is developed and revised as the design matures. This begins to risk inform the LBE event sequences with insights gained from the design phase PRA.

3. A review of the LBEs is performed at the end of the design phase to evaluate conservatisms in the selected events.

As noted before, the approach in this paper uses a blend of deterministic and probabilistic techniques, where deterministic evaluations provide initial identification of events and subsequent confirmation of margins through the evaluation of DBAs, and probabilistic components provide a systematic process to ensure all sequences are captured and properly classified. 


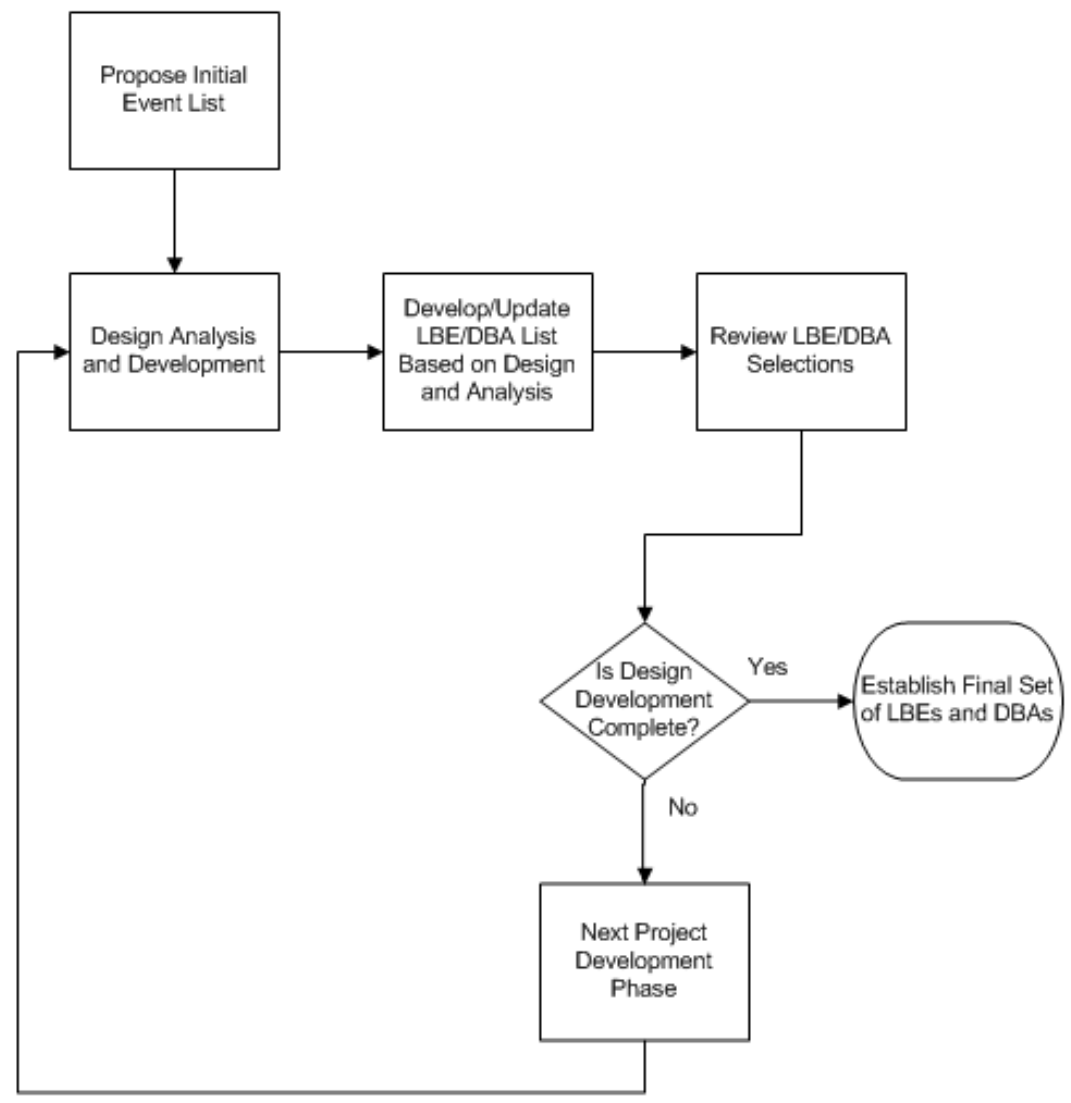

Figure 2. Basic LBE selection process.

\subsection{Conceptual Design Phase}

During the conceptual design phase, different design concepts are explored and alternatives are considered to arrive at a feasible set of alternatives for the HTGR design. Traditional design and analysis techniques are applied during conceptual design, including the (1) use of traditional design bases of engineering analysis and judgment, (2) application of research and development programs, (3) use of past design and operational experience, and (4) addressing of substantial conformance to established LWRbased reactor design criteria.

During conceptual design an initial set of events are proposed to provide a starting point for the design process. At this point, there is typically little design detail available and a design-specific PRA is not available to create an initial set of events. Therefore, deterministic engineering judgment is applied early in the LBE development process to create an initial event list that would be used to account for design-related uncertainties.

Creation of the initial event list includes expert evaluation and review of the experience gained from previous HTGR designs and associated PRAs. Once design alternatives are developed, a review of the major systems can take place and techniques such as a failure modes and effects analysis can be used to identify initial failure scenarios. 
Application of previous experience includes a review of event families that were considered by past HTGR concepts and projects, such as (but not limited to) the MHTGR, Fort St. Vrain, and the Exelon/PBMR effort. Typical events may include loss of primary coolant flow, ${ }^{\mathrm{g}}$ reactivity insertions, and helium pressure boundary failures, which can result in air and/or water ingress.

Once an initial set of events are identified, they would be subjected to expert evaluation and review processes to determine adequacy for starting the preliminary design phase. This set may later be revised or events removed as the design matures and PRA-based probabilistic insights are used to risk-inform the initial selection.

Section 2.1.1 described the NRC regulations that provide guidance for identification of unplanned transients and accidents for LWRs. However, many of these regulations are not directly applicable to HTGRs. This is because the safety philosophy of an HTGR does not depend on the helium coolant inventory, and there are no SSCs needed to perform the coolant inventory control functions of an emergency core cooling system as in LWRs. Therefore, LOCAs are characteristically different for an HTGR. Although LBEs for the HTGR are expected to include leaks and breaks in the helium pressure boundary. Such breaks are referred to as depressurization events rather than LOCAs.

\subsection{Preliminary Design Phase}

Preliminary design activities balance regulatory and design requirements, cost, schedule, and other factors to optimize the design, cost, and capabilities that satisfy the objectives for the HTGR facility. During this phase, the selected conceptual design will be developed into more detailed system designs.

As the design matures, the PRA is developed and the results will be used to risk-inform the initial set of LBEs that were selected during conceptual design. When the preliminary design is finalized, the design will be well defined, the configuration and performance requirements for the safety systems will be identified, and the PRA will be developed. At this point, the set of LBEs will be risk-informed by the process described in the remaining portions of Section 3.3. This set of LBEs (and DBAs) will form the basis of the safety analysis included in the license application.

\subsubsection{Use of PRA}

The PRA will be used to evaluate the safety characteristics of the preliminary design and to provide a structured framework from which the initial set of LBEs will be risk-informed. In addition, engineering judgment and utilization of HTGR experience will continue to be used to ensure that LBE selection and classification is complete. The rationale for use of risk-assessment techniques is as follows:

- Using a PRA to aid in the development of events that are included in the licensing basis maximizes the probability of establishing a comprehensive safety basis. By its nature, PRA development is a rigorous process that considers the comprehensive performance of the facility design.

- Probabilistic methods for event selection, SSC safety classification, special treatment identification, and integration of defense-in-depth strategies will seek to optimize the safety characteristics of the HTGR design.

- The PRA provides a rational approach for identifying, understanding, and addressing uncertainties.

The PRA will systematically enumerate event sequences and assesses the frequency and consequence of each event sequence. Event initiators will include internal, common cause, and external events.

g; Coolant inventory makeup is not applicable to HTGRs (because core heat removal does not rely solely on the coolant inventory), but core heat removal is addressed through evaluation of pressurized and depressurized loss-of-forced-cooling events. 
An event family is defined as a collection of event sequences that similarly challenge plant safety functions. The SSCs that perform the safety functions have a similar response, and the sequences have similar consequences. Event family grouping facilitates selection of LBEs from many individual events. For example, the PRA will likely include variations of helium pressure boundary breaks in terms of break size and location relative to the core and different compartments in the reactor building. A particular family of helium pressure boundary breaks combines many individual break locations and sizes found to have similar plant response to facilitate common analysis and consistent application of required preventive and mitigative functions.

The PRA's quantification of both frequencies and consequences will address uncertainties, especially those associated with the potential occurrence of rare events. The quantification of frequencies and consequences of event sequences, and the associated quantification of uncertainties, provides an objective means of comparing the likelihood and consequence of different scenarios against the TLRC. The scope of the PRA will be as comprehensive and sufficiently complete as a full-scope, all modes, Level 3 PRA covering a full set of LWR internal and external events. A white paper describing the proposed PRA development process will be provided in the future.

As noted in Section 2.1.2.1, the NRC is expecting greater emphasis on the use of risk information, provided there is sufficient understanding of plant and fuel performance and deterministic engineering judgment is used to bound uncertainties. The need for "sufficient understanding of plant and fuel performance" will be addressed by other white papers covering such topics as NGNP fuel qualification, NGNP high temperature materials, and NGNP mechanistic source terms.

\subsubsection{Safety Classification of SSCs}

The HTGR design may have one or more SSCs that are capable of performing a given safety function during an LBE to keep its consequences within the TLRC. The HTGR design team determines which SSCs shall be classified as safety-related. The approach includes using the PRA to provide information needed to classify SSCs and identify the appropriate level of special treatment necessary to assure functional performance. This is complemented with deterministic analysis and engineering judgment to provide an appropriate level of defense-in-depth (see white papers on the topics of NGNP SSCs safety classification and NGNP defense-in-depth approach).

\subsubsection{Event Categorization}

The TLRC establish limits on the frequencies and public radiological consequences used to classify and evaluate the LBEs that are refined during the preliminary design phase. Section 2.3 defined the criteria for establishing limits on the frequencies or consequences of LBEs and LBE categories. These safety design criteria provide the technical basis for ensuring that HTGR design meets applicable toplevel health and safety regulatory criteria, and that equipment important to reactor safety has the capability and the reliability needed to perform their intended safety functions. In other words, the TLRC establish what safety acceptance criteria must be met.

The spectrum of potential accidental radioactive releases from the HTGR plant is divided into three regions of a scenario frequency versus consequence chart. The regions include those associated with:

- AOOs

- DBEs

- BDBEs. 
These categories are defined by the mean frequency of the event family on a per-plant-year basis. AOOs, DBEs, and BDBEs are identified by the mean frequency of the event family that falls within the respective $\mathrm{AOO}, \mathrm{DBE}$, and $\mathrm{BDBE}$ regions of the frequency consequence chart.

\subsubsection{AOO Region}

AOOs are those conditions of plant operation expected to occur one or more times during the life of the plant. Current LWR plants were licensed to operate for an initial 40-year period; however, with the advent of license renewal, operating licenses of conventional LWRs have been increased for some plants by 20 years. Therefore, a conservative value of $1 \times 10^{-2}$ per plant year is used to establish the lower bound of the AOO region.

For this region, 10 CFR Part 20 provides the applicable criteria, as it specifies the numerical guidance to assure that releases of radioactive material to unrestricted areas during normal reactor operations, including AOOs, are maintained as ALARA. This provides the upper dose consequence limit of 100 mrem TEDE at the EAB. As noted earlier, for the NGNP facility, the EAB is expected to be the same area as the controlled area boundary. The $\mathrm{EAB}$ is defined as that area surrounding the reactor, in which the reactor licensee has the authority to determine all activities including exclusion or removal of personnel and property from the area. For the remainder of this paper, the term EAB will be used.

\subsubsection{DBE Region}

The DBE region encompasses releases that are not expected to occur during the lifetime of a single nuclear power plant, but they may be encountered during the lifetime of a population of nuclear power plants of similar design. Therefore, $1 \times 10^{-4}$ per plant-year is used to establish the lower bound of this region.

There is no need to require $10 \mathrm{CFR} \S 50.34$ to be met at frequencies lower than $10^{-4}$ per plant-year to meet the NRC Safety Goal QHOs; at $10^{-4}$ per plant-year they are met with margin. As discussed in Section 2.1.3, establishing $10^{-4}$ per plant-year as the lower frequency for the design basis region is consistent with LWR regulatory guidance for the design goal frequency of core damage events. As noted by Draft ANS Standard 53.1, "Nuclear Safety Design Process for the Design of Modular Helium-Cooled Reactor Plants" $"$ :

The adoption of the DBE region's lower frequency limit of $1 \times 10^{-4}(1 \mathrm{E}-04)$ per plant-year is appropriate because it is applied on a per-plant basis and accounts for possible multiple MHR modules. In addition, the expression of the frequency metric on a per plant-year basis enables the assessment to include event sequences involving only one or multiple reactor module source terms and thereby provides a more complete risk assessment as compared with the approach of analyzing each reactor module on an independent reactor-year basis.

For the DBE region, the 25 rem TEDE criterion in $10 \mathrm{CFR} \S 50.34 \mathrm{a}$ provides the quantitative dose guidance for accidental releases for siting a nuclear power plant to ensure that the surrounding population is adequately protected. The combination of the selected frequency limits and dose limits for the DBE region ensures that the NRC Safety Goal QHOs for individual risk of latent cancer fatality is met by several orders of magnitude for all event sequences within the DBE region.

\subsubsection{BDBE Region}

The BDBE region, comprising improbable events that are not expected to occur during the lifetime of a large fleet of nuclear power plants, should be considered to assure that the risk to the public from low 
probability events is acceptable. The BDBE region will consider events with a mean value below the DBE region's lower frequency limit of $1 \times 10^{-4}$ per plant-year.

The frequency cutoff implicit in the acute fatality risk goal in NUREG-0880, "Safety Goals for Nuclear Power Plant Operation," is taken as the lower frequency boundary of the BDBE Region. NUREG-0880 notes that the individual mortality risk of prompt fatality in the United States is about $5 \times 10^{-4}$ per year for all accidental causes of death. The prompt mortality risk design objective limits the increase in an individual's annual risk of accidental death to $0.1 \%$ of $5 \times 10^{-4}$, or an incremental increase of no more than $5 \times 10^{-7}$ per year. If the frequency of a scenario or set of scenarios is at or below this value, it can be assured that the individual risk contributions from these scenarios would still be within the safety goal, independent of the magnitude of the consequences with a significant residual margin.

\subsubsection{Selection of LBEs}

The next series of subsections describe the details related to applying the PRA results to the frequency-consequence (F-C) curve (Figure 3) that lead to refinement of the set of identified LBEs. The consequence limits associated with the above event categories are used to establish the F-C curve of dose consequence limits versus event frequencies. The selected frequency ranges are those associated with AOOs, DBEs, and BDBEs, respectively.

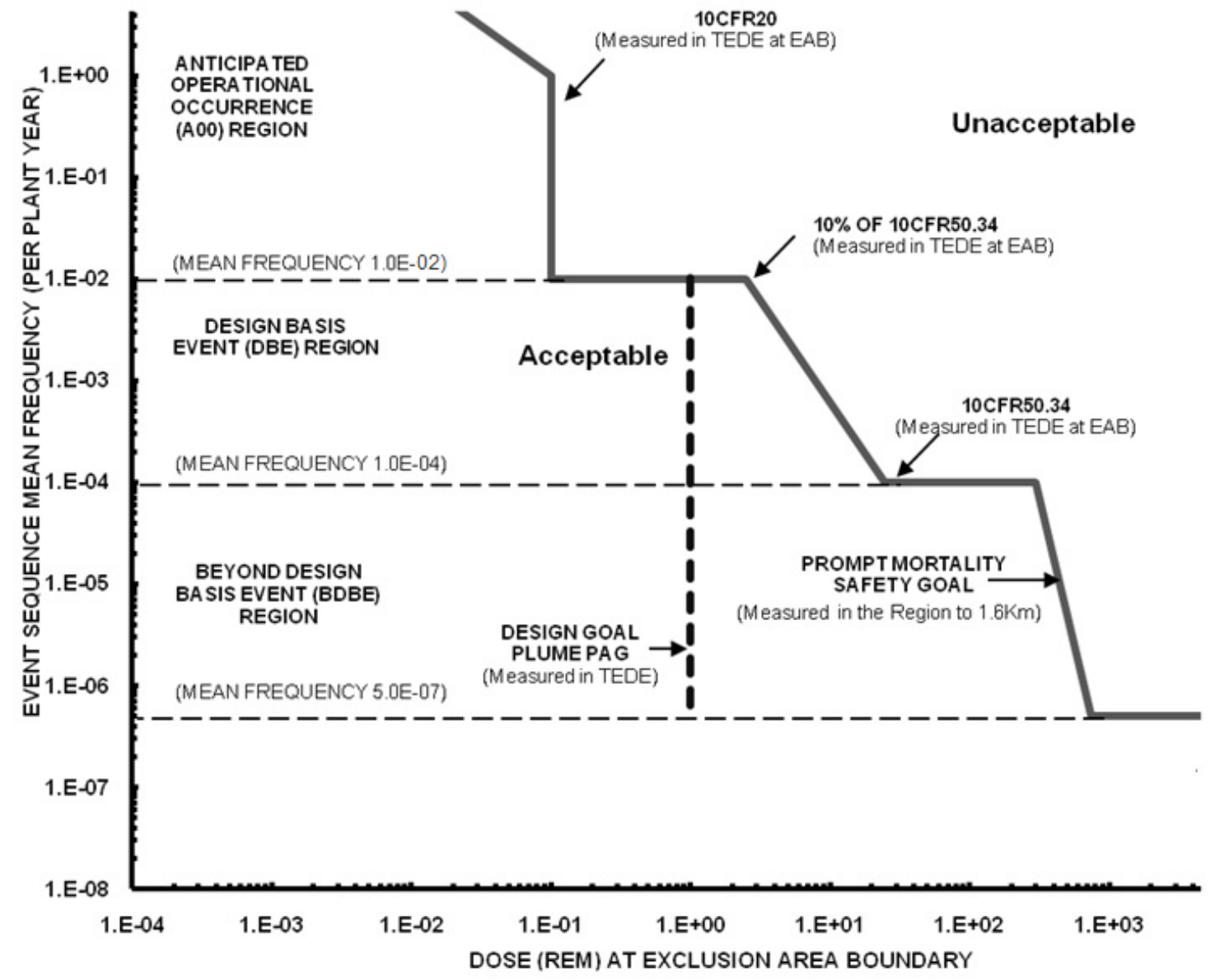

Figure 3. Frequency-consequence chart with top-level regulatory criteria. 
NOTE: The following subsections provide design-specific examples for the purpose of describing the LBE selection methodology. These examples are derived from a previous PBMR design that does not represent a proposed design for the NGNP project. Given that a design has not been selected, the readers should not assume that the systems described and the associated LBEs identified will have any relationship with the NGNP Project's eventual design. These examples are provided for illustrative purposes only.

\subsubsection{Selection of $A O O$}

The AOO range covers very frequent events expected to occur several times a year to events that are as rare as once in a hundred years during the life of a single reactor. The y-coordinate in Figure 3 is the mean or expected frequency expressed in per plant-year to include postulated releases from one or more reactors or sources within the plant. The x-coordinate is the mean or expected consequence to the public, so it is measured at the EAB. 10 CFR Part 20 is plotted in the figure as the limiting TLRC to encompass an acceptable and an unacceptable region for AOOs.

10 CFR Part 20 is shown with a break in the line at the frequency of once per year, since it is an annualized limit, that is, the sum of all releases in a given year should not exceed 0.1 rem to the whole body gamma dose. For example, only two events with a release of one-half of the 0.1 rem limit can occur per year. Events with frequencies less than once per year must each meet the 0.1 rem limit.

The next step is to plot the events from the PRA on the chart. As an example, an abbreviated PRA event tree for a loss of Power Conversion Unit (PCU) is provided in Figure 4, which is an event tree that illustrates the dominant branches in the PRA that result from a transient in which the normal operation of the PCU is lost. The initiating event frequency is shown as 3.5 per reactor-year. The event sequences start with the initiating event and proceed through the full event sequence, and if there are additional failures after the initiating event, they are included in the event sequence.

\begin{tabular}{|c|c|c|c|c|c|c|c|}
\hline Initiating Event & \multicolumn{4}{|c|}{ Response to Initiating Event } & \multirow{2}{*}{ 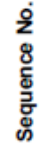 } & \multirow{2}{*}{$\begin{array}{c}\text { Event Sequence } \\
\text { Frequency } \\
\text { (/ Reactor-yr.) }\end{array}$} & \multirow[b]{2}{*}{ LBE Type } \\
\hline $\begin{array}{l}\text { Loss of Power } \\
\text { Conversion Unit }\end{array}$ & $\begin{array}{l}\text { Reactor Trip } \\
\text { via RCS/RSS }\end{array}$ & $\begin{array}{c}\text { Core Heat } \\
\text { Removal via } \\
\text { SBS }\end{array}$ & $\begin{array}{c}\text { Core Heat } \\
\text { Removal via } \\
\text { CCS }\end{array}$ & $\begin{array}{c}\text { Core Heat } \\
\text { Removal via } \\
\text { RCCS }\end{array}$ & & & \\
\hline
\end{tabular}

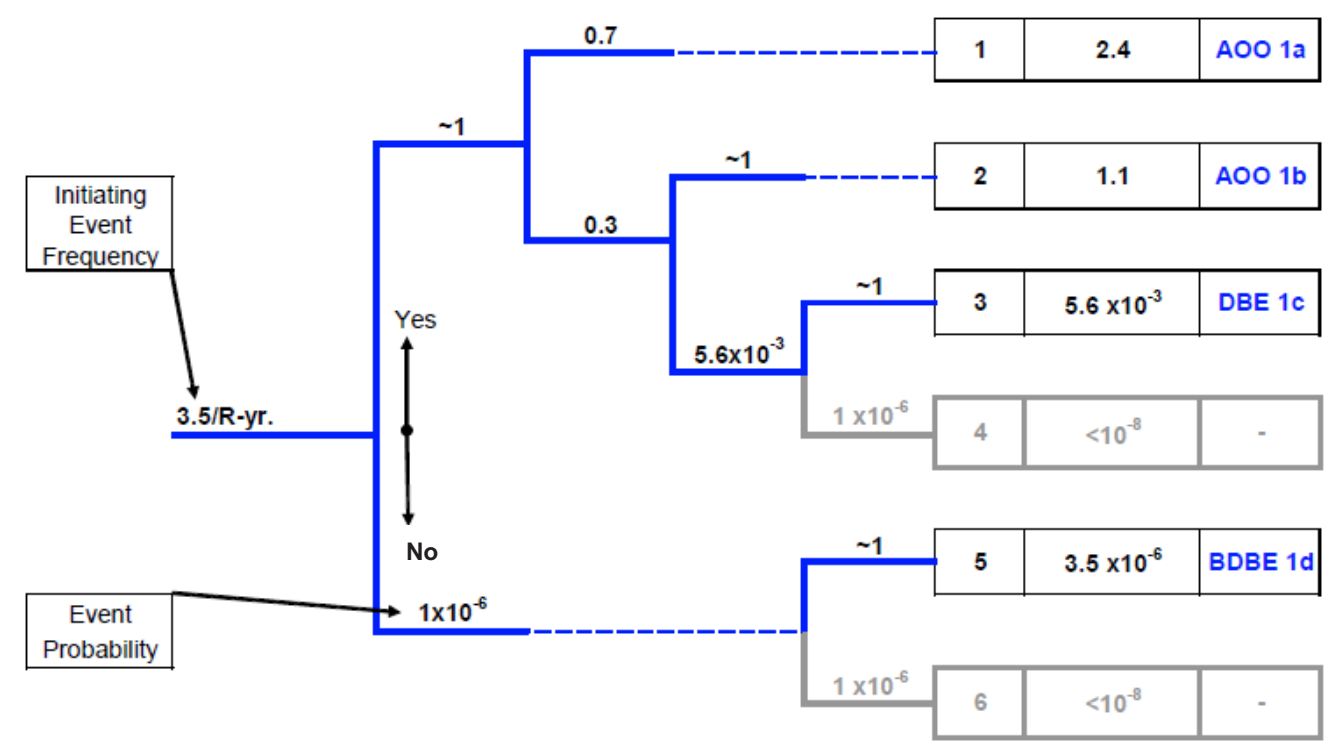

Figure 4. Event tree for loss of PCU. 
The first branch in the tree is related to tripping the reactor by automatically or manually inserting the Reactivity Control System (RCS) control rods or the Reserve Shutdown System (RSS) backup poison material. As shown, successful functions are in the upward direction. The succeeding branches all relate to the core heat removal function.

In the example design, three systems are available for this function: the Start-up Blower System (SBS), the Core Conditioning System (CCS), and the Reactor Cavity Cooling System (RCCS). The first two involve the forced convection of the helium coolant through the core to heat exchangers to transport the heat, while the RCCS relies on passive natural convection, conduction, and radiation heat transfer from the core through the uninsulated reactor vessel to surrounding water tanks. In the example design, the RCCS has an active mode in which the water in the tanks is circulated through a heat exchanger and a passive mode in which the water in the tanks boils off. Figure 4 shows the event sequence families for each of these three cases, labeled AOO 1a, AOO 1b, and DBE 1c, respectively.

Event sequence families are used to group together two or more event sequences when the sequences have a common initiating event, safety function response, and end state. The process of defining event sequence families applies the following considerations:

- The guiding principle is to aggregate event sequences to the maximum extent possible while preserving the functional impacts of the initiating event, safety function responses, and end state. Without event sequence families, excessive detail defining initiating events and balancing event and fault trees could obscure AOO, DBE, or BDBE event sequence classification. By aggregating sequences into family structures, the event sequence model leaves LBE classification essentially unaffected.

- The safety-function responses are delineated to a necessary and sufficient degree to identify unique challenges to each SSC that performs a given safety function along the event sequence.

- In many cases for a single module plant, there may be only one event sequence in the family.

- For a multimodule plant, event sequence families are used to combine event sequences that involve individual reactor modules independently into a single family of single reactor module event sequences.

- Each event tree initiating event and safety function response has a corresponding fault tree that delineates the event causes and SSC failure modes that contribute to the frequencies and probabilities of these events.

A common situation that yields accident families is when two or more initiating events belonging to the same functional category are quantified through the event trees separately, but follow the same event tree model and end states. For example, for the Figure 4 loss of PCU initiating event tree, separate initiating events were developed for the main contributors to the initiating event, e.g. turbine failure, bypass valve failure, loss of secondary water flow, but since the event sequences follow the same event tree logic and result in the same end states, they are aggregated into a family.

Figure 5 takes the PRA results from the event trees and shows the event frequencies and consequences on the Figure 3 chart. In these examples, the events with the same initiating event are labeled with the same numerical designation and depicted in the same color. Different sequences within a given initiating event tree are denoted by an alphabetical letter following the initiating event number.

AOOs are selected from those families of events whose mean frequency falls within the AOO region (as shown in Figure 5) and that would exceed the 10 CFR Part 20 criteria on a mean value basis if it were not for design selections that control radionuclide release. 


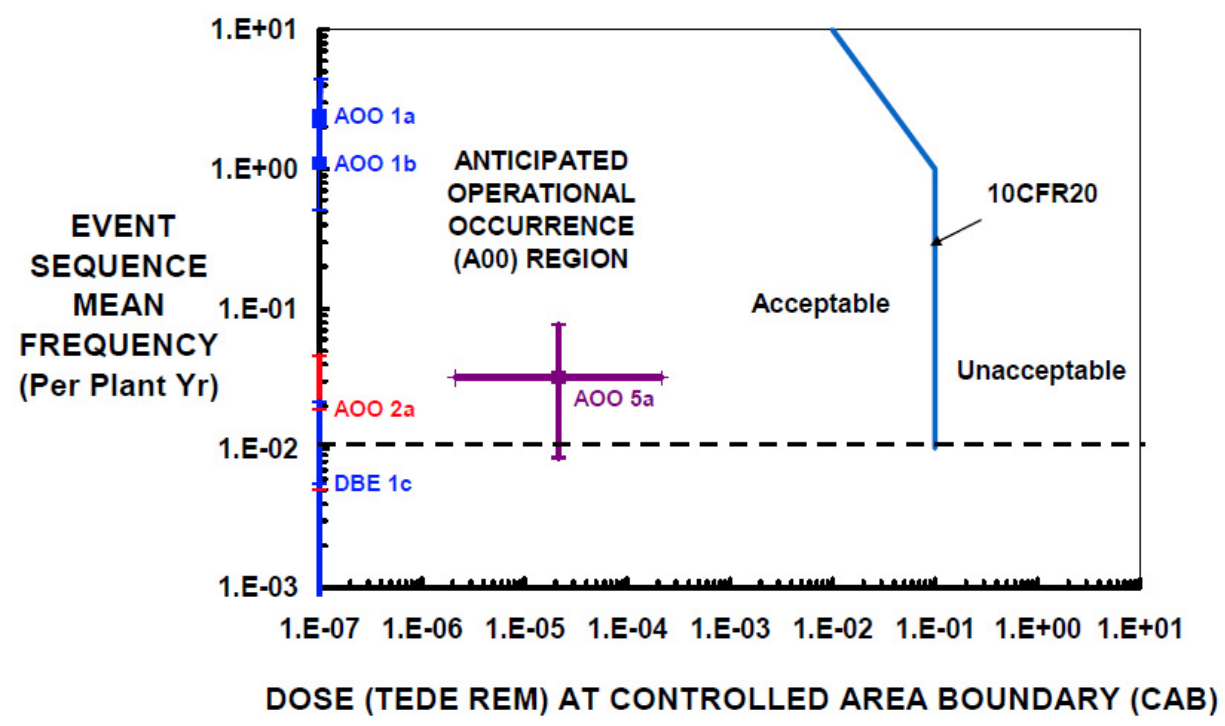

Figure 5. Use of PRA to select AOOs.

Events may have significant uncertainties in the estimate of their frequencies and consequences. The consideration of these uncertainties is necessary to ensure that all events will be assessed against the appropriate criteria. The mean value of frequency is the selected parameter for accounting for frequency uncertainties.

In addition, the upper and lower uncertainty bands are shown on the event points in Figure 5. If the upper bound frequency of an event (whose mean frequency is $<10^{-2}$ ) is above the $10^{-2}$ per plant-year lower frequency range of AOOs, it is evaluated as an AOO as well as a DBE. DBE-1c (mean frequency $=$ $5.6 \times 10^{-3}$ ) is an example whose event sequence is shown in the Figure 4 abbreviated event tree in which a loss of the CCS leads to heat removal with the RCCS. Since it has an upper bound frequency that exceeds $10^{-2}$ per plant-year, it is shown on the AOO plot.

AOOs typically have relatively small consequences associated with them. Only one of the AOOs shown in Figure 5, AOO 5a, has a non-zero consequence. Furthermore, individual plant-component operating data, component and event monitoring, and performance data over plant life ensure that AOO consequence uncertainties remain small. Therefore, although the PRA assessment provides the entire consequence distribution, including the mean, and upper and lower bound doses, it is proposed that the consequences of AOOs meet 10 CFR Part 20 criteria on a mean-value basis.

\subsubsection{Selection of DBEs}

Figure 6 is utilized for the selection of DBEs. The figure plots the 10 CFR $\$ 50.34$ limit on a frequency-consequence chart over the frequency range of $10^{-2}$ to $10^{-4}$ per plant-year. There are a number of similarities with the corresponding AOO chart, including the:

- Event sequence frequency is measured in events per plant-year

- Dose is measured at the EAB.

However, 10 CFR $\$ 50.34$ doses are measured in TEDE units, which take into account the relative importance of the various doses such as whole body gamma and thyroid in arriving at a weighted health effect to an individual. Since DBEs are not expected in the plant lifetime, there is no summation of frequent events as in the 10 CFR Part 20 case for AOOs. 
The 10 CFR $\$ 50.34$ limit is 25 rem TEDE per event sequence. However, recognizing that more frequent events in the upper frequency range of DBEs should have a lower consequence limit, a value of $10 \%$ of the limit has been assigned to the top of the DBE region. See Section 3.3.6 for discussion and application of the Protective Action Guide (PAG) design goal.

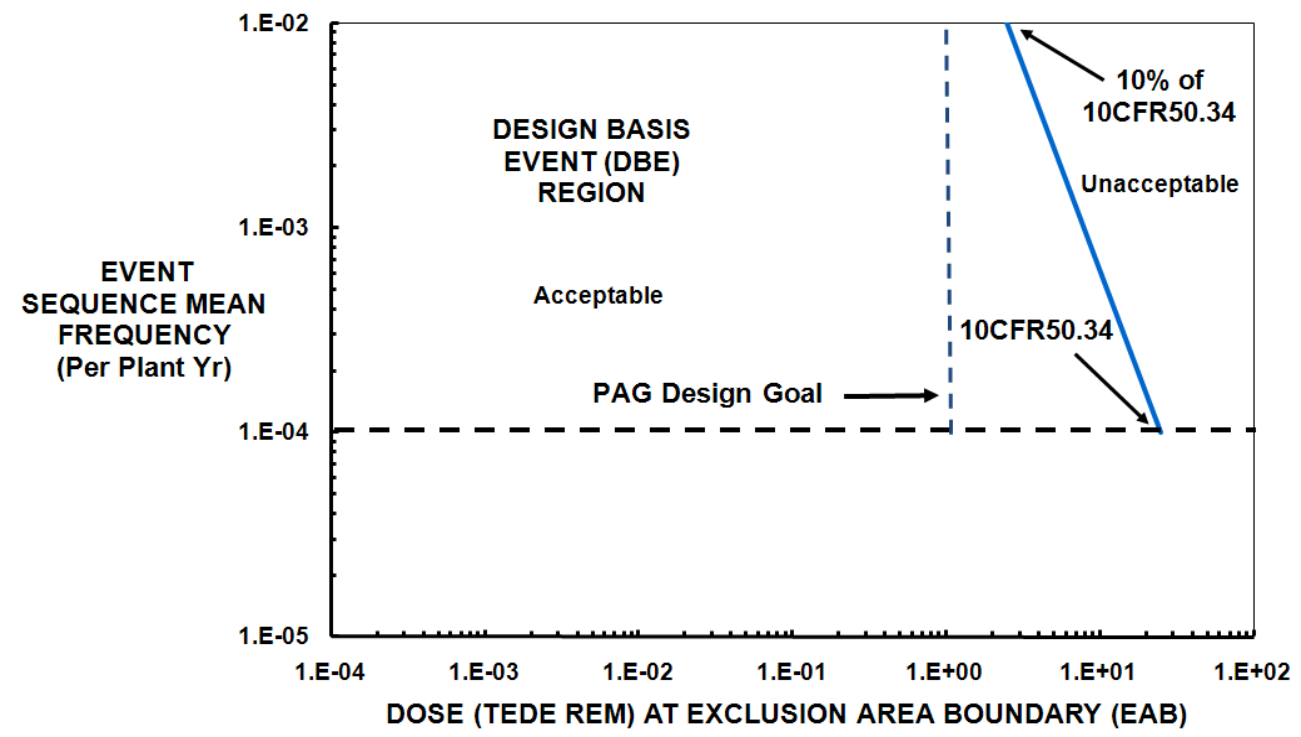

Figure 6. Frequency-consequence chart for DBEs.

Figure 7 shows the next step in the process for DBE selection with the PRA results plotted on the DBE frequency-consequence chart. Similar to AOOs, DBEs are selected from those families of events whose mean frequency falls within the DBE region and that would exceed the $10 \mathrm{CFR}$ \$50.34(a) dose criteria on a mean value basis if not for design selections that control radionuclide release. Those that meet this condition are designated as DBEs.

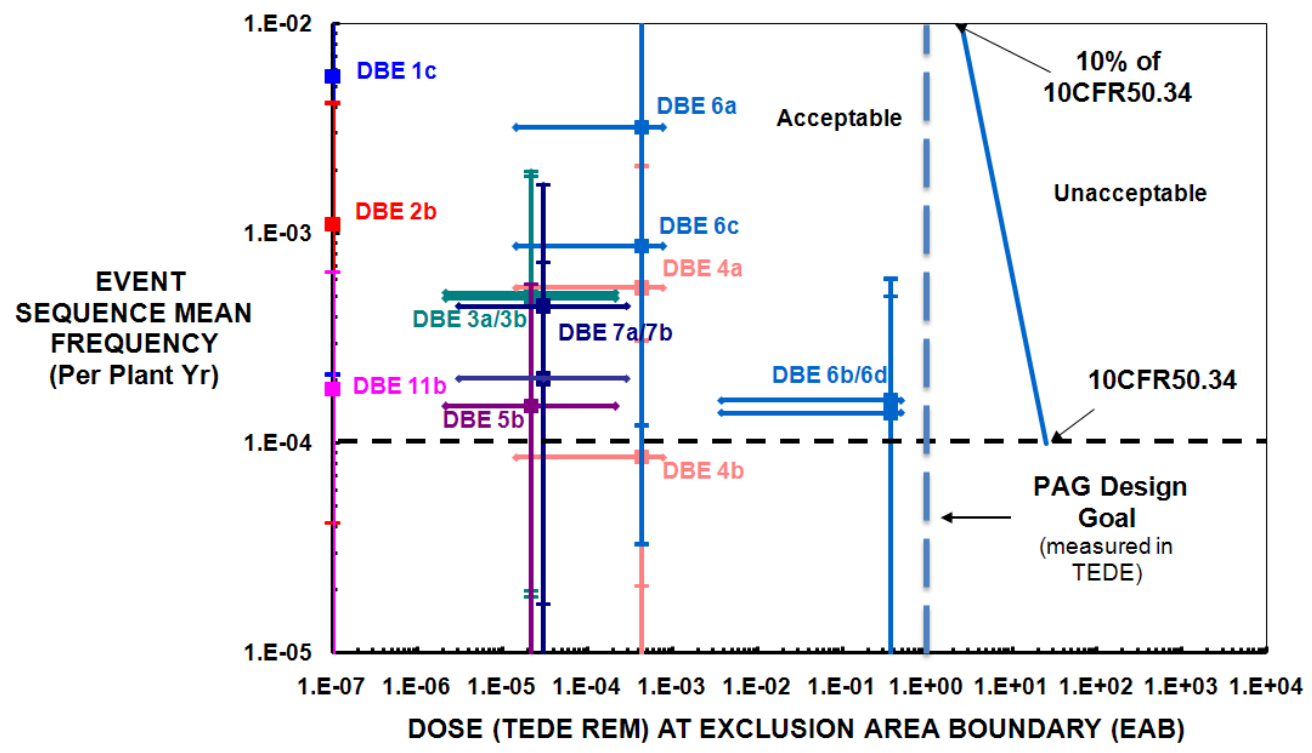

Figure 7. Use of PRA to select DBEs. 
The example results shown in Figure 7 indicate that the DBE dose limit was met. Note however, the larger uncertainties, particularly in the frequencies. As before, all DBEs must meet the 10 CFR $\S 50.34$ limit. The approach does not take the most limiting event with respect to dose, for example DBE-6, and assume that because it meets the $10 \mathrm{CFR} \S 50.34$ limit that the safety design of the DBEs is complete. Because different DBEs may rely upon different SSCs to achieve acceptable results, the NGNP project proposes to use the results of its analyses of all DBEs to define a complete set of the SSCs that impact the range of events.

\subsubsection{Selection of BDBEs}

BDBEs form an important element of the licensing basis to assure that the overall risk to the public is acceptably low and that adequate emergency planning is in place to address these highly improbable events. BDBEs are selected from those families of events with doses whose mean frequency falls within the BDBE region as shown in Figure 8. The mean public consequences of the BDBEs are the relevant measures of acceptance. As discussed in prior sections, the limiting TLRC for DBEs is the dose limit of 10 CFR $\$ 50.34$. There is not a corresponding dose limit shown on the figure for BDBEs on a per event basis. However, BDBEs (together with the AOOs and DBEs) are evaluated in a cumulative manner and compared in terms of individual risk to the reactor safety goals.

The NRC safety goal acute fatality is shown on the plot as a bounding limit in that it is plotted at the EAB. If each BDBE meets this limit, the cumulative risk of all LBEs will meet the NRC safety goals with large safety margins as discussed in Section 3.3.6.

Events below the $5 \times 10^{-7}$ per plant-year BDBE region are examined to assure that the residual risk is negligible with respect to the latent mortality safety goal, and to provide general assurance that no potentially high consequence events go unnoticed.

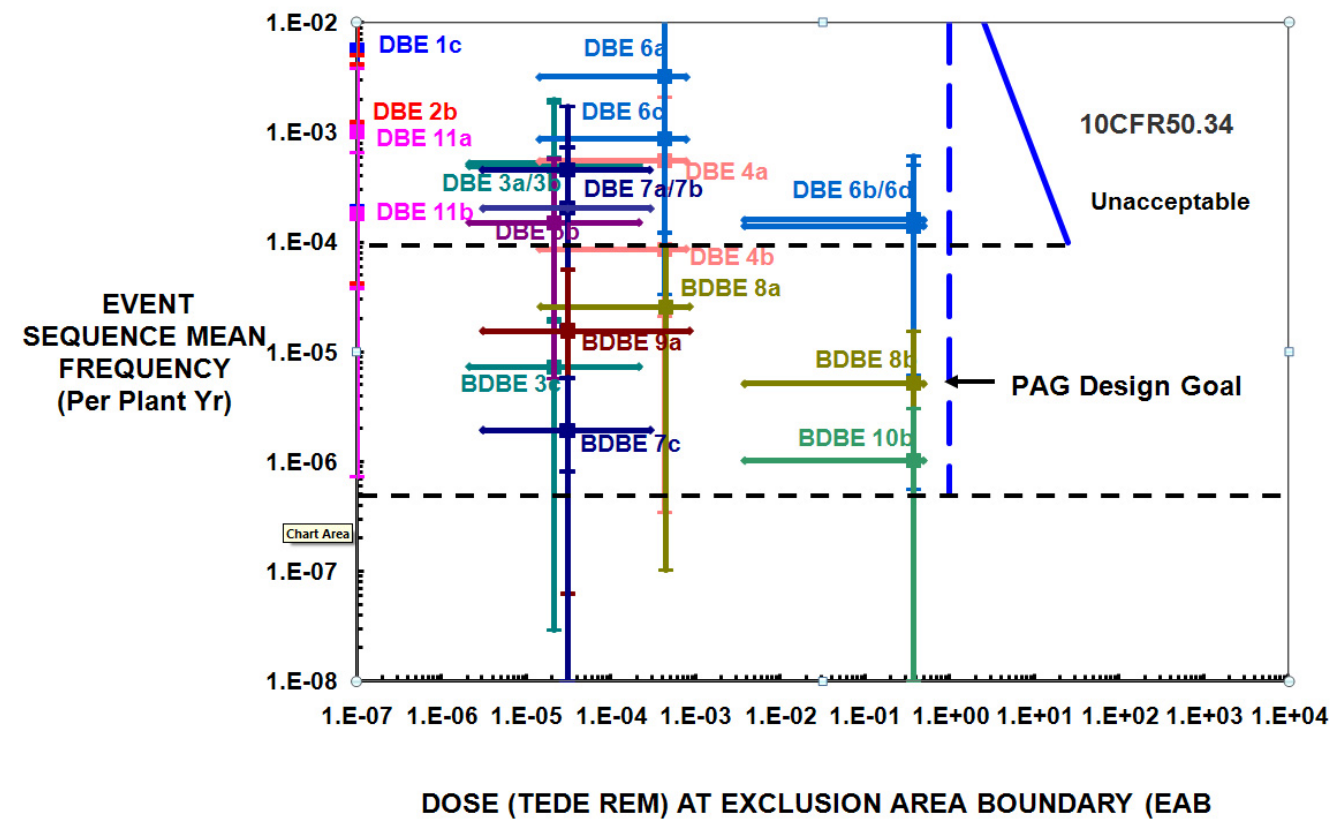

Figure 8. Use of PRA to select BDBEs. 


\subsubsection{DBAs for Safety Analysis Report Chapter 15 Evaluation}

DBAs correspond to the traditional LWR DBAs analyzed in Chapter 15 of the Safety Analysis Report. The approach in this paper allows the transition to be made from the traditional deterministic plant response with only safety-related SSCs responding to DBAs to all SSCs responding to DBEs, so that both the conservative and expected plant behavior are understood.

As noted in Section 3.1, an initial set of prospective LBEs is identified from which to make some of the basic design decisions and to provide a basis for an initial set of DBAs. This iterative process is performed initially to support the design and is later refined as more information is gained from the design process and development of the PRA.

Once the design matures, DBAs are identified by assuming that only SSCs classified as safety-related are available to perform the safety functions required to meet $10 \mathrm{CFR} \S 50.34$. After the safety-related SSCs are selected, all of the DBEs are reanalyzed with only the safety-related SSCs responding in a mechanistically conservative manner.

DBAs generally do not have the same sequence of events as corresponding DBEs, since the latter consider the expected plant response with all SSCs responding, whether safety-related or not. This means that some of the DBAs would have frequencies that are lower than the DBE frequency cutoff of $10^{-4}$.

Figure 9 shows the DBA-6 superimposed on the main power system heat exchanger break abbreviated event tree. The safety-related SSCs are shown in red font. For this example, the SSCs indicated are assumed to perform the required functions for reactor shutdown and core heat removal. The other SSCs are assumed to not be available. The approach to safety classification is the subject of a separate white paper. Thus, DBA-6, which considers only the response of the safety-related SSCs, is identical to DBE-6d and bounds DBE-5b and DBE-6a, 6b, and 6c.

Even with the consolidation of the DBEs into a smaller number of DBAs, there is still a spectrum of challenges that must be addressed based on the initiating event and on the progression of the events.

\subsubsection{Event Consequence Evaluation}

The preceding subsections have discussed the selection, classification, and refinement of the LBEs and DBAs. Although the frequencies and consequences of the LBEs have been shown on the frequencyconsequence charts, the emphasis of the discussion has been on the frequency of the event sequence families in relation to the three LBE regions. This subsection summarizes the approach to the consequence evaluation.

For each LBE and DBA, mechanistic source terms will be developed that evaluate the realistic response of the plant to the initiating event. The initial radionuclide inventories during the modes of normal operation will include, as appropriate those in the fuel, the circulating activity, the plateout activity within the helium pressure boundary, the spent and used fuel, and radioactive waste systems. See the white paper on mechanistic source term for a discussion on developing event source terms for reactor core-related radionuclide inventories.

For each of these inventories, the response to the initiating event of the barriers and that of the passive and active SSCs that protect those barriers will be modeled. The constituents of the uncertainty bands on the TEDE doses shown in the previous figures will be presented. Mechanistic source terms for the consequences for DBAs will also be evaluated in the same fashion, although for these deterministic accidents only safety-related SSCs respond. 


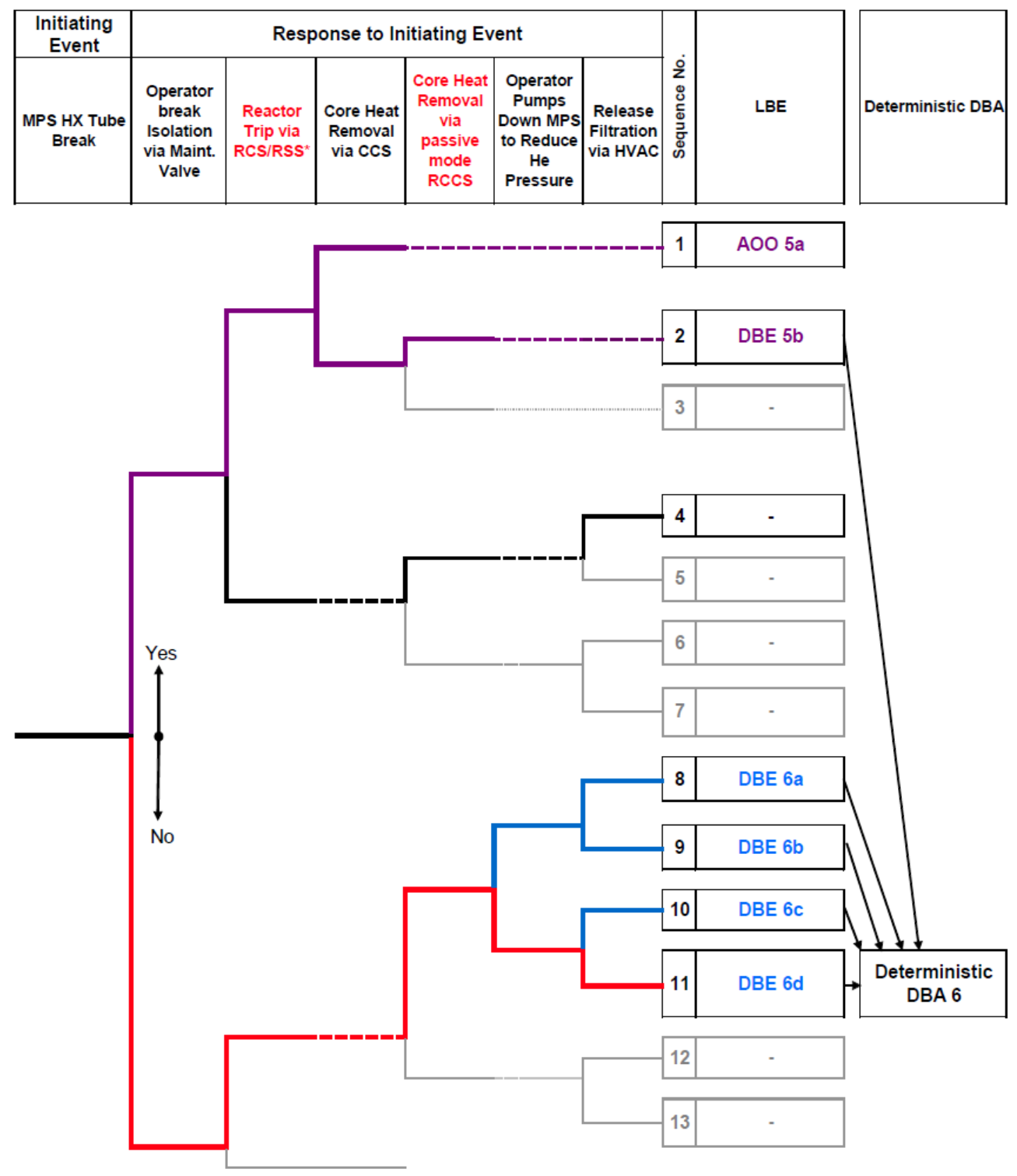

* safety-related SSCs shown in red font

Figure 9. Example of DBA for main power system hx initiating event.

The appropriate measure of acceptance varies for each category of LBE as follows:

- AOO: The consequence distribution for each AOO will be compared to the public consequence limit shown in Figure 3. The acceptance criterion is that the expected or mean consequence of the AOO must be less than the 100 mrem TEDE limit (or the appropriate fraction thereof) at the EAB as indicated in the figure.

- DBEs: The consequence distribution for each DBE is compared to the public consequence limit shown in Figure 3. The acceptance criterion is that the upper bound of the mean consequence of each DBE must be less than the 25 rem TEDE limit (or appropriate fraction thereof) at the EAB as indicated in the figure. 
- BDBEs: The consequence distribution for each BDBE is compared to the public consequence limit shown in Figure 3. The acceptance criterion is that the mean consequence of each BDBE must be less than the public consequence limit at the $\mathrm{EAB}$ as indicated in the figure.

The consequence distribution for each BDBE, together with the AOOs and DBEs, is compared to the safety goals as discussed in the next subsection.

The appropriate measure of acceptance for the DBAs is as follows:

- DBAs: The consequence distribution for each DBA is compared to the 10 CFR $\$ 50.34$ public consequence limit. The acceptance criterion is that the upper bound of the mean consequence of each DBA must be less than the 25 rem TEDE limit at the EAB.

For events involving more than one reactor module, the consequences from each involved reactor module are summed prior to comparison to the acceptance criterion. A future NGNP white paper will discuss this topic in greater detail.

\subsubsection{Cumulative LBE Evaluation}

In addition to meeting the F-C curve limits for individual events, the overall integrated risk of all event sequences from the plant PRA is to be evaluated to show that the calculated plant risk meets the reactor safety goals.

The qualitative reactor safety goals are discussed in NUREG-0880 in terms of quantitative health objectives.

The following quantitative health objectives are used in determining satisfactory achievement of the above safety goals:

- The risk to an average individual in the vicinity of a nuclear power plant of prompt fatalities that might result from reactor accidents should not exceed one-tenth of one percent $(0.1 \%)$ of the sum of prompt fatality risks resulting from other accidents to which members of the U.S. population are generally exposed.

- The risk to the population in the area near a nuclear power plant of cancer fatalities that might result from nuclear power plant operation should not exceed one-tenth of one percent $(0.1 \%)$ of the sum of cancer fatality risks resulting from all other causes.

The prompt fatality QHO limits the increase in an individual's risk of prompt fatality to $0.1 \%$ of that from all "other accidents to which members of the U.S. population are generally exposed," which is about $5 \times 10^{-4}$ per year. Therefore the incremental prompt cancer risk goal established by the Reactor Safety Goals is $5 \times 10^{-7}$ fatalities/year. The 'vicinity' of a nuclear power plant is understood to be a distance extending to 1 mile from the plant site boundary.

The latent fatality QHO limits the increase in an individual's annual risk of death to $0.1 \%$ of $2 \times 10^{-3}$ per person-year, or an incremental increase of no more than $2 \times 10^{-6}$ per person-year. For this QHO, the 'area' is understood to be an annulus of 10-mile radius from the plant site boundary. The cancer risk is also determined on the basis of an average individual risk, i.e., by evaluating the number of latent cancers (societal risk) resulting from all accidents to a distance of 10 miles from the plant site boundary, weighted by the frequency of the accident, dividing by the total population to 10 miles, and summing over all accidents.

The NGNP project has a design objective to meet the PAGs at the EAB. By meeting this design objective, it is clear that the prompt safety goal will be met by orders of magnitude. By meeting the PAG 
( 1 rem for an early release) at the EAB for all LBEs, the sum of the average risk of a prompt fatality from all accidents to an individual will be less than the prompt fatality goal with significant margin.

By meeting the PAG at the EAB for all LBEs, the sum of the average risk of a latent fatality from all accidents to an individual will be expected to be demonstrated to be less than the latent fatality goal.

Another way of stating the result is that if all events including the BDBEs meet the dose limits at the $\mathrm{EAB}$, then the QHOs within the larger distances from the site are met with large margins.

\subsubsection{Final Set of LBEs}

Once the process described in this section is complete, the initial set of LBEs will be risk-informed. A final review of the refined list of LBEs will be performed to evaluate the conservatisms in the selected events. This will be done to ensure adequate margins exist for the LBEs and identify any areas where it may be beneficial for the designer to take credit for large available design margins. If the designer decides to revise the design in order to take credit for some available design margin, the FSAR Chapter 15 analyses will be reevaluated and reconfirmed to ensure that adequate safety margins remains.

Once this evaluation is complete, the refined set of LBEs (and DBAs) will form the basis of the safety analysis content included in the license application.

\subsection{Final Design Phase}

The final design phase marks the completion of the design effort and production of all the approved design documentation necessary to support procurement, construction, and facility testing, including detailed facility drawings.

During the final design phase, project personnel will be monitoring the details related to completion of the final design work to identify any impacts on the final set of LBEs and DBAs. In particular, the ongoing research and development activities will be monitored to ensure that research results are evaluated for potential impacts on existing safety analysis results. Any outstanding safety analysis work related to the LBEs and DBAs will be completed during this phase. As noted above, the FSAR Chapter 15 analyses will be confirmed to ensure that adequate safety margins are maintained. 


\section{OUTCOME OBJECTIVES}

The information provided in this white paper is intended to serve as the basis for interaction with the NRC staff. Section 1.4 introduced a set of outcome objectives that require interactions with the NRC regarding selection and classification of LBEs.

The NGNP Project is seeking (1) NRC's general concurrences and/or comments on the adequacy of the planned LBE selection approach and (2) to obtain feedback from the NRC on any issues that have the potential to significantly impact the effort and schedule to prepare an application for a first-of-a-kind HTGR plant under the NGNP Project. The following are specific areas where agreement on the NGNP Project's approach to the selection and classification of LBEs is being sought. A summary of the NGNP approach for each outcome objective is also provided.

1. The structured process for selecting LBEs is an acceptable approach for defining the LBEs.

NGNP Approach: An acceptable approach starts with a deterministically selected initial event list. It then includes a design-specific PRA with the following elements: an engineering analysis of the plant response to each initiating event using verified computer models, deterministic success criteria, and conservative deterministic safety analyses of DBAs in Chapter 15 of the license application.

Both the deterministic and probabilistic analysis will be supported by a comprehensive and systematic search for initiating events, including internal events and internal and external plant hazards that could occur during all operating and shutdown modes, and covering the sources of radioactive material.

2. LBEs cover a comprehensive spectrum of events from normal operation to rare, off-normal events. There are three categories of LBEs:

a. AOOs which encompass planned and anticipated events. The doses from AOOs are required to meet normal operation public dose requirements. AOOs are utilized to set operating limits for normal operation modes and states.

b. DBEs encompass unplanned, off-normal events not expected in the plant's lifetime, but which might occur in the lifetimes of a fleet of plants. The doses from DBEs are required to meet accident public dose requirements. DBEs are the basis for the design, construction, and operation of the SSCs during accidents.

c. BDBEs, which are rare, off-normal events of lower frequency than DBEs. BDBEs are evaluated to ensure that they do not pose an unacceptable risk to the public.

The LBEs in all three categories will be evaluated individually to support the tasks of assessing the performance of SSCs with respect to safety functions in response to initiating events and collectively to demonstrate that the integrated risk of a multimodule plant design meets the NRC safety goals.

NGNP Approach: The three categories of LBEs and their purposes adhere to the existing NRC regulations and policy. The LBEs include AOOs, DBEs, and BDBEs used in NRC regulatory policy and guidance. DBEs, as well as AOOs and BDBEs, are selected through the use of the PRA and are based on a realistic response of the entire plant. This is the necessary foundation for understanding the safety functions and the SSCs available to perform them. This leads to the safety classification of SSCs, which is the subject of another paper. Once the SSC safety classification is known, the deterministically selected initial event list is risk-informed by DBAs that are derived from the DBEs by demonstrating success paths for the DBAs relying solely on their response of safety-related SSCs, as in the conventional regulatory practice. 
3. The frequencies of LBEs are expressed in units of events per plant-year where a plant is defined as a collection of reactor modules having certain shared systems. The limits on the frequency ranges for the LBE categories are as follows:

a. AOOs - event sequences with mean frequencies greater than $10^{-2}$ per plant-year

b. DBEs - event sequences with mean frequencies less than $10^{-2}$ per plant-year and greater than $10^{-4}$ per plant-year

c. BDBEs - event sequences with mean frequencies less than $10^{-4}$ per plant-year and greater than $5 \mathrm{x}$ $10^{-7}$ per plant-year.

NGNP Approach: For AOOs, the NGNP Project proposes a lower frequency limit of $10^{-2}$ per plantyear. For DBEs, NGNP Project proposes a lower frequency range for event sequences of $10^{-4}$ per plant-year, which meets the NRC safety goals and is consistent with LWR regulatory practice. For BDBEs, NGNP Project proposes a lower limit of $5 \times 10^{-7}$ per plant-year.

To account for multimodule concepts, the NGNP Project proposes that the frequency be stated on a per plant-year basis. For example, the frequency for a $10^{-4}$ per plant-year event impacting only one of an eight reactor module facility is $1.25 \times 10^{-5}$ per plant-year. For events impacting more than one and up to all eight reactor modules, such as earthquakes, the frequency is $10^{-4}$ per plant-year and the consequences will take into account all eight reactor modules. By setting the lower bound of the DBE region at $10^{-4}$ per plant-year, NGNP is committing to design for all events, whether impacting one reactor module or all the reactor modules.

4. Acceptable limits on the event sequence consequences and the analysis basis for the LBE categories are as follows:

a. AOOs - 10 CFR Part 20: 100 mrem TEDE mechanistically modeled and realistically calculated at the $\mathrm{EAB}$

b. DBEs - 10 CFR $\S 50.34$ : 25 rem TEDE mechanistically modeled and conservatively calculated at the $\mathrm{EAB}$

c. BDBEs - NRC safety goal QHOs mechanistically and realistically calculated at 1 mile $(1.6 \mathrm{~km})$ and 10 miles $(16 \mathrm{~km})$ from the plant.

NGNP Approach: The acceptable public consequences have been derived from the existing regulations and policy in Section 2. In summary, the limits in 10 CFR Part 20 are applied to AOOs and the limits in 10 CFR $\$ 50.34$ are applied to the DBEs and the DBAs. The safety goal QHOs are applied to all the LBEs in a cumulative manner. The analyses bases follow the conventional practice for each of the LBE categories and respective TLRC.

5. The frequency below which events are not selected as LBEs is $5 \times 10^{-7}$ per plant-year. The PRA examines events to $10^{-8}$ per plant-year to assure that there are none just below this de minimus frequency.

NGNP Approach: BDBEs will meet the NRC safety goals at the prescribed distances from the plant. The NGNP project proposes $5 \times 10^{-7}$ per plant-year, since lower frequency events by definition meet the NRC safety goal QHO for acute individual risk of fatality.

6. The kinds of events, failures, and natural phenomena that are evaluated include:

a. Multiple, dependent, and common cause failures to the extent that these contribute to LBE frequencies 
b. Events affecting more than one reactor module

c. Internal events (including transients and accidents) and internal and external plant hazards that occur in all operating and shutdown modes and potentially challenge the capability to satisfactorily retain any source of radioactive material.

NGNP Approach: The PRA supporting the application will be a full scope (including all operating modes) evaluation. A future NGNP white paper will discuss this topic in greater detail.

7. The DBAs for Chapter 15, "Accident Analysis," of the license application are derived from the DBEs by assuming that only SSCs classified as safety-related are available to mitigate the consequences. The public consequences of DBAs are based on mechanistic source terms and are conservatively calculated. The upper bound consequence of each DBA must meet the $10 \mathrm{CFR} \S 50.34$ consequence limit at the EAB.

NGNP Approach: The DBAs will be derived from the DBEs by considering only the response of SSCs classified as safety-related. The consequences of DBAs will be based on mechanistic source terms and will be conservatively calculated. The upper bound consequence of each DBA will meet the $10 \mathrm{CFR} \S 50.34$ consequence limit at the EAB.

8. Uncertainty distributions are evaluated for the mean frequency and the mean consequence for each LBE. The mean frequency is used to determine whether the event sequence family is an AOO, DBE, or BDBE. If the upper or lower bound on the LBE frequency straddles two or more regions, the LBE is compared against the consequence criteria for each region. The mean, lower, and upper bound consequences are explicitly compared to the consequence criteria in all applicable LBE regions. The upper bound for the DBE and DBA consequences must meet the 10 CFR $\$ 50.34$ dose limit at the EAB.

NGNP Approach: Uncertainty distributions will be evaluated for the mean frequency for each LBE. The mean frequency will be used to determine whether the event sequence family is an AOO, DBE, or BDBE. If the upper or lower bound on the LBE frequency straddles two regions, the LBE will be compared against the consequence criteria for each region. 


\section{REFERENCES}

1. U.S. Nuclear Regulatory Commission, 'Use of Probabilistic Risk Assessment Methods in Nuclear Regulatory Activities; Final Policy Statement,' Federal Register, Vol. 60, No. 158, August 16, 1995.

2. Regulatory Guide 1.174, 'An Approach for Using Probabilistic Risk Assessment in Risk- informed Decisions on Plant Specific Changes to the Current Licensing Basis,' U.S. Nuclear Regulatory Commission, Revision 1, issued 11/2002.

3. U.S. Nuclear Regulatory Commission, 'Policy Statement on the Regulation of Advanced Reactors; Final Policy Statement,' Federal Register, Vol. 73, No. 199, pp.60612-60616, October 14, 2008.

4. SECY 2003-0047, 'Policy Issues Related to Licensing Non-Light Water Reactor Designs,' U.S. Nuclear Regulatory Commission, March 28, 2003.

5. SRM 2003-0047, 'Staff Requirements Memorandum for SECY 03-0047 - Policy Issues Related to Licensing Non-Light Water Reactor Designs,' U.S. Nuclear Regulatory Commission, June 26, 2003.

6. U.S. Nuclear Regulatory Commission, 'Standard Review Plan for the Review of Safety Analysis Reports for Nuclear Power Plants (NUREG-0800),' Revision 2, June 1987.

7. SRM-90-16, 'Evolutionary Light Water Reactor (LWR) Certification Issues and Their Relationship to Current Regulatory Requirements,' U.S. Nuclear Regulatory Commission, June 26, 1990.

8. Standard Review Plan 19, 'Use of Probabilistic Risk Assessment in Plant-Specific, Risk- informed Decisionmaking: General Guidance,' NUREG-0800, U.S. Nuclear Regulatory Commission, Revision 1, November 2002.

9. Regulatory Guide 1.200, 'An Approach for Determining the Technical Adequacy of Probabilistic Risk Assessment Results for Risk-informed Activities,' U.S. Nuclear Regulatory Commission, for Trial Use, February 2004.

10. U.S. Nuclear Regulatory Commission, 'Safety Goals for the Operations of Nuclear Power Plants; Policy Statement,' Federal Register, Vol. 51, No. 149, pp. 28044-28049, August 4, 1986 (republished with corrections, Vol. 51, No. 160, pp. 30028-30023, August 21, 1986).

11. U.S. Nuclear Regulatory Commission, 'Policy Statement on Severe Reactor Accidents Regarding Future Designs and Existing Plants,' Federal Register, Vol. 50, No. 153, pp. 32138-32150, August 8, 1985.

12. Draft ANS Standard 53.1, "Nuclear Safety Design Process for the Design of Modular Helium-Cooled Reactor Plants."

13. U.S. Nuclear Regulatory Commission, 'Safety Goals for Nuclear Power Plant Operation (NUREG0880),' Revision 1, May 1993. 